NASA/TM-2010-215676

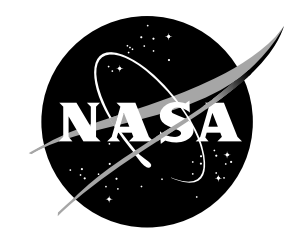

\title{
Aerodynamic Simulation of Runback Ice Accretion
}

Andy P. Broeren

Glenn Research Center, Cleveland, Ohio

Edward A. Whalen

The Boeing Company, St. Louis, Missouri

Greg T. Busch and Michael B. Bragg

University of Illinois, Urbana, Illinois 


\section{NASA STI Program . . . in Profile}

Since its founding, NASA has been dedicated to the advancement of aeronautics and space science. The NASA Scientific and Technical Information (STI) program plays a key part in helping NASA maintain this important role.

The NASA STI Program operates under the auspices of the Agency Chief Information Officer. It collects, organizes, provides for archiving, and disseminates NASA's STI. The NASA STI program provides access to the NASA Aeronautics and Space Database and its public interface, the NASA Technical Reports Server, thus providing one of the largest collections of aeronautical and space science STI in the world. Results are published in both non-NASA channels and by NASA in the NASA STI Report Series, which includes the following report types:

- TECHNICAL PUBLICATION. Reports of completed research or a major significant phase of research that present the results of NASA programs and include extensive data or theoretical analysis. Includes compilations of significant scientific and technical data and information deemed to be of continuing reference value. NASA counterpart of peer-reviewed formal professional papers but has less stringent limitations on manuscript length and extent of graphic presentations.

- TECHNICAL MEMORANDUM. Scientific and technical findings that are preliminary or of specialized interest, e.g., quick release reports, working papers, and bibliographies that contain minimal annotation. Does not contain extensive analysis.

- CONTRACTOR REPORT. Scientific and technical findings by NASA-sponsored contractors and grantees.
- CONFERENCE PUBLICATION. Collected papers from scientific and technical conferences, symposia, seminars, or other meetings sponsored or cosponsored by NASA.

- SPECIAL PUBLICATION. Scientific, technical, or historical information from NASA programs, projects, and missions, often concerned with subjects having substantial public interest.

- TECHNICAL TRANSLATION. Englishlanguage translations of foreign scientific and technical material pertinent to NASA's mission.

Specialized services also include creating custom thesauri, building customized databases, organizing and publishing research results.

For more information about the NASA STI program, see the following:

- Access the NASA STI program home page at http://www.sti.nasa.gov

- E-mail your question via the Internet to help@ sti.nasa.gov

- Fax your question to the NASA STI Help Desk at 443-757-5803

- Telephone the NASA STI Help Desk at 443-757-5802

- Write to: NASA Center for AeroSpace Information (CASI) 7115 Standard Drive Hanover, MD 21076-1320 
NASA/TM-2010-215676

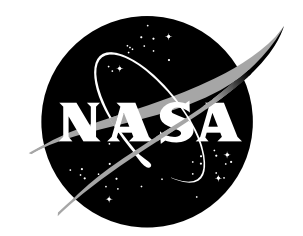

\section{Aerodynamic Simulation of Runback Ice Accretion}

Andy P. Broeren

Glenn Research Center, Cleveland, Ohio

Edward A. Whalen

The Boeing Company, St. Louis, Missouri

Greg T. Busch and Michael B. Bragg

University of Illinois, Urbana, Illinois

National Aeronautics and

Space Administration

Glenn Research Center

Cleveland, Ohio 44135 


\section{Acknowledgments}

This work was funded by the Federal Aviation Administration (FAA) Office of Aviation Research. While at the University of Illinois, the authors were supported under FAA grant DTFA 96-G-023, with Jim Riley as the contracting officer's technical representative. Additional support, including the use of wind-tunnel models and ancillary equipment, was provided by the NASA Glenn Research Center. This support is gratefully acknowledged.

Level of Review: This material has been technically reviewed by technical management.

Available from

NASA Center for Aerospace Information 7115 Standard Drive

Hanover, MD 21076-1320
National Technical Information Service 5301 Shawnee Road Alexandria, VA 22312

Available electronically at http://gltrs.grc.nasa.gov 


\section{TABLE OF CONTENTS}

Page

EXECUTIVE SUMMARY

vii

1. INTRODUCTION 1

2. EXPERIMENTAL METHODS 3

2.1 The ONERA F1 Wind Tunnel and Model 3

2.2 University of Illinois Wind Tunnel and Model 7

2.3 Full-Scale Model Ice-Shape Simulation Methods 8

2.4 Subscale Model Ice-Shape Simulation Methods 10

3. RESULTS AND DISCUSSION 13

3.1 Full-Scale Results 13

3.2 Subscale Simulation of Runback Ridge Aerodynamics 21

3.3 Aerodynamic Classification of Spanwise Ridge Ice 28

4. CONCLUSIONS 35

5. REFERENCES 36 


\section{LIST OF FIGURES}

Figure

Page

1 Schematic of the ONERA F1 Pressurized Wind Tunnel

2 Photograph of the Full-Scale NACA 23012 Airfoil Model Installed in ONERA F1 Wind Tunnel Test Section

3 Photograph of Subscale NACA 23012 Airfoil Model Installed in University of Illinois Wind Tunnel Test Section

$4 \quad$ Photograph of NG0671 Runback Ice Accretion Casting

5 Tracing of NG0662 Runback Ice Accretion Formed at Conditions Identical to the NG0671 Casting Shown in Figure 4

6 Completed Installation of Runback Ridge Simulation NG0671 on the Leading Edge of the Full-Scale NACA 23012 Model

7 Tracing of Runback Ice Casting NG0671 on the NACA 23012 Leading Edge

8 Photographs of Subscale Model Upper-Surface Ridge Simulations

$9 \quad$ Photographs of Subscale Model Ridge Simulations

10 Comparison of Clean and Iced NACA 23012 Airfoil Performance for Various

High-Fidelity, Ice-Casting Simulations at $R e=16.0 \times 10^{6}$ and $M=0.20$

11 Various Ice-Casting Simulations Tested by Broeren, et al. on the Full-Scale NACA 23012 Airfoil Model

12 Comparison of Clean and Iced NACA 23012 Airfoil Pressure Distribution for Various High-Fidelity, Ice-Casting Simulations at $\alpha=4.2^{\circ}, R e=16.0 \times 10^{6}$, and $M=0.20$

13 Comparison of Clean and Iced NACA 23012 Airfoil Pressure Distribution for Various Angles of Attack at $R e=16.0 \times 10^{6}$ and $M=0.20$

14 Effect of Reynolds Number on the Performance of the NACA 23012 Airfoil With the NG0671 Ice Casting at $M=0.10$

15 Effect of Reynolds Number on the Performance of the NACA 23012 Airfoil With the NG0671 Ice Casting at $M=0.20$

16 Effect of Mach Number on the Performance of the NACA 23012 Airfoil With the NG0671 Ice Casting at $R e=12.2 \times 10^{6}$ 
17 Effect of Reynolds Number on Maximum Lift Coefficient for the NACA 23012 Airfoil for Clean and Iced Configurations

18 Effect of Mach Number on Maximum Lift Coefficient for the NACA 23012 Airfoil for Clean and Iced Configurations

19 Comparison of $C_{l}, C_{m}$, and $C_{d}$ vs $\alpha$ for the Clean Subscale Model and the Full-Scale NG0671 Casting and Clean Configurations

20 Comparison of $C_{l}, C_{m}$, and $C_{d}$ vs $\alpha$ for Various Subscale Runback-Ridge Simulations and the Full-Scale NG0671 Casting and Clean Configurations

21 Comparison of Surface Pressure Distribution for Selected Subscale Runback-Ridge Simulations (at $R e=1.8 \times 10^{6}, M=0.18$ ) and the Full-Scale NG0671 Casting and Clean Configurations (at $R e=16.0 \times 10^{6}, M=0.20$ ), all at $\alpha=12.4^{\circ}$

22 Comparison of $C_{l}, C_{m}$, and $C_{d}$ vs $\alpha$ for Various Subscale Runback-Ridge Simulations and the Full-Scale NG0671 Casting and Clean Configurations

23 Effect of Reynolds and Mach Number on the Subscale Runback-Ridge Simulation Performance Effects

24 Surface Pressure Effect of Square-Cylinder Spanwise Ridge Height at $x / c=0.16$ on the Upper Surface of the NACA 3415 Airfoil at $R e=1.8 \times 10^{6}, M=0.18$

25 Comparison of Separation Bubble Reattachment Location Based on Surface-Oil Flow Visualization Results for Tall and Short Spanwise Ridges, all Data at $R e=1.8 \times 10^{6}, M=0.18$

26 Mean and rms Velocity Profiles Downstream of $k / c=0.0035$ Square-Cylinder Ridge Shape Located at $x / c=0.16$ on the NACA 3415 Airfoil With $\alpha=8^{\circ}$, $R e=1.8 \times 10^{6}$, and $M=0.18$

27 Mean and rms Velocity Profiles Downstream of $k / c=0.0069$ Square-Cylinder Ridge Shape Located at $x / c=0.16$ on the NACA 3415 Airfoil With $\alpha=8^{\circ}$, $R e=1.8 \times 10^{6}$, and $M=0.18$

28 Surface Pressure Effect of $k / c=0.0035$ Square-Cylinder Spanwise Ridge Chordwise Location on the Upper Surface of the NACA 3415 Airfoil at $\alpha=12^{\circ}$, $R e=1.8 \times 10^{6}$, and $M=0.18$ 


\section{LIST OF TABLES}

Table

Page

$1 \quad$ Matrix of Reynolds and Mach Number Conditions

2 Estimated Experimental Uncertainties for Measurements in the ONERA F1 Wind Tunnel

3 Estimated Experimental Uncertainties for Measurements in the University of Illinois Wind Tunnel

$4 \quad$ Summary of Runback-Ridge Ice Simulations

5 Summary of Subscale Model Simulation Effectiveness for the NG0671 Ice Casting 


\section{EXECUTIVE SUMMARY}

This report presents the results of recent investigations into the aerodynamics of simulated runback ice accretion on airfoils. Aerodynamic tests were performed on a full-scale model using a high-fidelity, ice-casting simulation at near-flight Reynolds $(R e)$ number. In addition, followon subscale tests were conducted with low-fidelity simulations on a quarter-scale model at low Reynolds number. The ice-casting simulation was attached to the leading edge of a 72-inch (1828.8-mm) chord National Advisory Committee for Aeronautics (NACA) 23012 airfoil model. Aerodynamic performance tests were conducted at the Office National d'Etudes et de Recherches Aérospatiales (French Aeronautics and Space Research Center) (ONERA) F1 pressurized wind tunnel over a Reynolds number range of $4.7 \times 10^{6}$ to $16.0 \times 10^{6}$ and a Mach $(M)$ number range of 0.10 to 0.28 . For $R e=16.0 \times 10^{6}$ and $M=0.20$, the simulated runback ice accretion on the airfoil decreased the maximum lift coefficient from 1.82 to 1.51 and decreased the stalling angle of attack from $18.1^{\circ}$ to $15.0^{\circ}$. The pitching-moment slope was also increased and the drag coefficient was increased by more than a factor of two. In general, the performance effects were insensitive to Reynolds and Mach number changes over the range tested.

The results from the full-scale tests were used to evaluate aerodynamic simulation methods for runback ice accretion. Aerodynamic tests were conducted on a quarter-scale NACA 23012 model (18-inch (457.2-mm) chord) at $R e=1.8 \times 10^{6}$ and $M=0.18$, using low-fidelity, geometrically scaled simulations of the full-scale casting. Simple, two-dimensional simulations of the upper- and lower-surface runback ridges provided the best representation of the full-scale, high Reynolds number iced-airfoil aerodynamics. Higher-fidelity simulations of the runback ice accretion that included geometrically scaled three-dimensional features resulted in larger performance degradations than the full-scale model. At this time, it is not clear why a simple, two-dimensional, geometrically scaled ridge simulation is required to best represent the fullscale, high Reynolds number, iced-airfoil aerodynamics. Reynolds number effects between the subscale model $\left(1.8 \times 10^{6}\right)$ and full-scale model (at $\left.4.7 \times 10^{6}\right)$ may be significant and more research is recommended.

A new subclassification of spanwise ridge ice that distinguishes between short and tall ridges is proposed. This subclassification is based upon the flow field and resulting aerodynamic characteristics, regardless of the physical size of the ridge and the ice-accretion mechanism. Tall spanwise ridges have a profound effect on the airfoil flow field with a large (and often unsteady) separation bubble that grows rapidly with angle of attack and precipitates stall at a much lower lift coefficient and angle of attack than other ice accretions. In contrast, short spanwise ridges are characterized by a small, stable separation bubble formed in the immediate vicinity of the ridge. This small separation zone results in a limited effect on the airfoil pressure distribution relative to the clean configuration. Significant differences in surface pressure are only observed at the ridge location. The separation bubble does not significantly increase in size with angle of attack. Thus, the stall of the iced airfoil is generally governed by trailing-edge separation moving forward with increasing angle of attack (trailing-edge stall). In some cases, the airfoil may stall from the leading edge or from the ridge itself. More research is needed to determine the appropriate simulation methods for short ridges, particularly for Reynolds numbers less than $1.8 \times 10^{6}$. 



\section{INTRODUCTION.}

Many aircraft certified for flight in icing conditions employ anti-icing systems on wing and empennage leading edges, as well as engine nacelles and other aerodynamic surfaces. In some cases, these ice-protection systems allow some fraction of the impinging water to flow downstream from the protected region and freeze, leaving a ridge-type ice accretion. Understanding the aerodynamic effects associated with runback icing is important to ensuring safety of flight operations and reducing development and certification costs. It is difficult and expensive to document the aerodynamic effect of this type of ice accretion in natural icing conditions. Therefore, simulations are often used to represent the ice accretion in a wind tunnel, sometimes on a subscale model at lower-than-flight Reynolds number. Subsequent questions naturally arise regarding the fidelity of the simulated ice accretion and Reynolds number effects.

Many of these same issues surround iced-airfoil aerodynamics in general and have recently been addressed in the Airfoil Ice Accretion Aerodynamics Simulation research program sponsored by the National Aeronautics and Space Administration (NASA) and the Office National d'Etudes et de Recherches Aérospatiales (French Aeronautics and Space Research Center) (ONERA) [1]. This program quantified many of the uncertainties associated with various subscale simulation methods developed to capture the essential aerodynamic features of the full-scale iced airfoil. The authors considered four types of ice accretion classified by their unique aerodynamics: roughness, streamwise ice, horn ice, and spanwise ridge ice. The aerodynamic characteristics of the spanwise ridge ice accretion were developed from research related to large ice accretions downstream of protected surfaces typically formed in supercooled large drop (SLD) conditions. These may be referenced to as tall spanwise ridges, such that the flow field is characterized by a large separation bubble aft of the ridge. This leads to significant airfoil performance penalties, often surpassing that of horn ice. However, as shown in this report, runback ridges do not usually exhibit this type of flow field. Spanwise ridges resulting from anti-icing systems tend to be shorter in height above the airfoil surface, cover a larger surface length, and have a more streamlined geometry. They may be referenced to as "short" due to their reduced impact on the iced-airfoil aerodynamics. Regardless of the ice accretion mechanism, the aerodynamics of "tall" and "short" ridges are significantly different, thus leading to a subclassification of spanwise ridge ice. Bragg, et al. [2] allude to this case in their review of iced-airfoil aerodynamics. This comparison is covered in more detail in this report.

Aerodynamic performance data for runback ice accretion (or any high-fidelity simulation) on airfoils or wings are scarce in the public domain. Gray and von Glahn [3] documented the associated drag increases due to runback ice accretion in an icing wind tunnel, but were unable to conduct these and other performance measurements over a significant angle of attack range. Calay, et al. [4] simulated runback ice accretion ridges using a step, a ramp, and a triangular shape, each with a normalized height, $k / c=0.0035$ on a National Advisory Committee for Aeronautics (NACA) 0012 airfoil at $R e=1.25 \times 10^{6}$ and $M=0.08$. They found that the drag coefficient at $0^{\circ}$-angle of attack increased by up to approximately 0.011 , while maximum lift coefficient decreased by up to 0.35 with the shapes at $x / c=0.05$. Calay, et al. [4] also found that the same simulations, when located at $x / c=0.15$, increased $C_{1, \max }$ of the airfoil. The greatest $\mathrm{C}_{\mathrm{l}, \max }$ increase was approximately 0.08 and $\alpha_{\text {stall }}$ was delayed by $1^{\circ}$. The authors noted that the stall of the airfoil with the ice simulations began from the artificial ice shapes rather than from 
the trailing edge, as was the case for the clean airfoil. The increase in $\mathrm{C}_{l, m a x}$ was attributed to the flow remaining attached at greater angles of attack than in the clean case. The mechanism by which this occurred was not discussed except to note that the shape added "extra turbulence." Calay, et al. [4] concluded that small changes in the artificial ice shapes were able to produce large changes in performance effects, thus requiring accurate simulations to properly estimate aerodynamic effects. Papadakis and Gile-Laflin [5] also observed performance increases near maximum lift due to a backward facing ramp with $k / c=0.0041$ at $x / c=0.15$ and a spoiler with $k / c=0.0053$ at $x / c=0.15$. Their tests were conducted using a modified NACA $63_{\mathrm{A}}-213$ airfoil at $R e=2.0 \times 10^{6}$ and $M=0.17$. The ramp increased $\mathrm{C}_{\mathrm{l}, \max }$ by 0.11 and delayed stall by $4^{\circ}$ while the spoiler increased $\mathrm{C}_{l, \max }$ by 0.01 and delayed stall by $1^{\circ}$. Tests with the ramp farther forward on the airfoil, at $x / c=0.025$ reduced $C_{l, m a x}$ by 0.23 and the stalling angle of attack by $2^{\circ}$. These reports indicate mixed results in performance for simulated runback ridges. Relative to the clean, or uniced airfoil, increases in drag were always observed. However, these artificial ice shapes increased the maximum lift coefficient and stalling angle of attack in some cases. Such increases run contrary to the recent body of research associated with tall, SLD-type spanwise ridge ice accretion [6-8].

Whalen, et al. [9 and 10] investigated the aerodynamic performance penalties of scaled, runbacktype ice accretions on NACA 23012 and NACA 3415 airfoils at $R e=1.8 \times 10^{6}$ and $M=0.18$. The ice accretions that these simulations were based on were generated on a full-scale model at the NASA Glenn Icing Research Tunnel (IRT). The results indicated that runback ice accretion can significantly degrade the aerodynamic performance of airfoils, particularly for ridges located near the airfoil leading edge. It was also shown that, for the shortest accretions, these effects were more sensitive to the height of the simulation.

Whalen, et al. [9 and 10] also found that the performance penalties associated with simple, twodimensional simulations of runback ice accretion did not agree well with higher-fidelity simulations that included roughness and a more accurate ice-shape profile. Both simulations were geometrically scaled based upon the ratio of the chord length of the aerodynamic model to that of the icing model. Results similar to the aforementioned studies [4 and 5] were observed. A simple, square-cylinder simulation $(k / c=0.0035)$ caused an increase in maximum lift and stalling angle of attack for the NACA 3415 airfoil and had a negligible effect on the maximum lift and stalling angle of attack of the NACA 23012. Further investigation revealed that this simulation was similar in height to the boundary-layer thickness. The source of this performance effect was linked to the shape's ability to generate a mixing layer that entrained highermomentum fluid into the boundary layer while generating a small, stable separation bubble. The effect was more pronounced in the case of the NACA 3415 because it exhibits a trailing-edge stall, unlike the NACA 23012, which stalls from the leading edge at the test Reynolds number. Trailing-edge stall can be effectively mitigated by increasing the momentum in the airfoil boundary layer.

The effects observed for the runback-ridge simulations aroused suspicion as to the appropriate method for developing subscale simulations. Geometric scaling had been used in the past with good success [8 and 11]. Busch, et al. [12], in particular, provide quantitative assessment of ice accretion simulation methods on a quarter-scale model at low Reynolds numbers. The lift performance increases due to the two-dimensional simulations observed by Whalen, et al. [9 and 
10] were generally not expected and did not agree with the results for higher-fidelity simulations. Because the simulations were similar in height to the local boundary-layer thickness, it was theorized that the boundary-layer thickness may be the appropriate length scale. Tests conducted by Whalen, et al. [9 and 10] using two-dimensional boundary-layer-scaled simulations, which were approximately twice as tall as the geometrically scaled simulations, showed significant penalties that were in better agreement with (geometrically scaled) higher-fidelity simulations of warm-hold runback ice accretion. However, without aerodynamic performance results at fullscale Reynolds number, it was difficult to draw a definitive conclusion concerning the scaling of these shapes. Lee, et al. [13] investigated geometry and Reynolds number scaling of a runback ice accretion on a business-jet wing. They found that geometric scaling did not reproduce the aerodynamics of the full-scale wing with the runback-type spanwise ridge. Empirical methods were used to develop aerodynamically equivalent shapes that represented the full-scale, icedwing aerodynamics on the subscale wing. Reynolds number effects were also found to be significant for this ice shape, unlike the case of the large, leading-edge ice shape that was also tested.

These recent results from subscale model tests at lower-than-flight Reynolds number clearly show the need for high-fidelity, high Reynolds number aerodynamic data. Therefore, a key objective of this work was to determine the effect of a high-fidelity runback ice accretion simulation on airfoil aerodynamic performance at near-flight Reynolds number and quantify the Reynolds number effects. In addition, follow-on subscale tests were conducted with low-fidelity simulations at low Reynolds number to provide information about the accuracy of aerodynamic simulation methods for small runback-type ice accretion. The first objective was achieved by conducting aerodynamic performance tests at the ONERA F1 pressurized wind-tunnel using a 72-inch (1828.8-mm) chord NACA 23012 airfoil over a Reynolds number range of $4.7 \times 10^{6}$ to $16.0 \times 10^{6}$ and a Mach number range of 0.10 to 0.28 . The high-fidelity simulation of the runback ice accretion was developed from an anti-icing system test in the NASA IRT. The second objective was achieved by conducting aerodynamic performance tests in the University of Illinois low-speed wind tunnel using an 18-inch (457.2-mm) chord NACA 23012 airfoil at a Reynolds number of $1.8 \times 10^{6}$ and a Mach number of 0.18 . Subscale simulations of the runback ice accretion, fabricated using simple-geometric shapes and roughness, were tested on the airfoil for comparison to the full-scale results. Finally, these results were used to further define the aerodynamic characteristics of spanwise ridge ice. A subclassification is proposed that distinguishes between tall and short spanwise ridges based upon their respective aerodynamic effects.

\section{EXPERIMENTAL METHODS.}

\subsection{THE ONERA F1 WIND TUNNEL AND MODEL.}

The full-scale aerodynamic tests were performed at the ONERA F1 pressurized wind tunnel facility, shown schematically in figure 1 [14]. The closed-return wind tunnel has a test section measuring 138 inches $(3500 \mathrm{~mm})$ high by 177 inches $(4500 \mathrm{~mm})$ wide by 433 inches $(11000 \mathrm{~mm})$ long. The maximum test section Mach number is 0.36 and the maximum stagnation pressure is 57 psia (3.85 bar). The unit Reynolds number can be varied up to a maximum of $6.0 \times 10^{6} / \mathrm{ft}$ at $\mathrm{Mach}=0.23$. Total temperature is maintained via a heat exchanger (i.e., "water 
cooler" in figure 1) located in the second diffuser downstream of the fan. The fan operates at constant speed while the test section Mach number is controlled by adjusting the pitch of the blades. The test section inlet flow is conditioned through a 7.18-to-1 contraction containing a honeycomb flow straightener and three turbulence reduction screens.

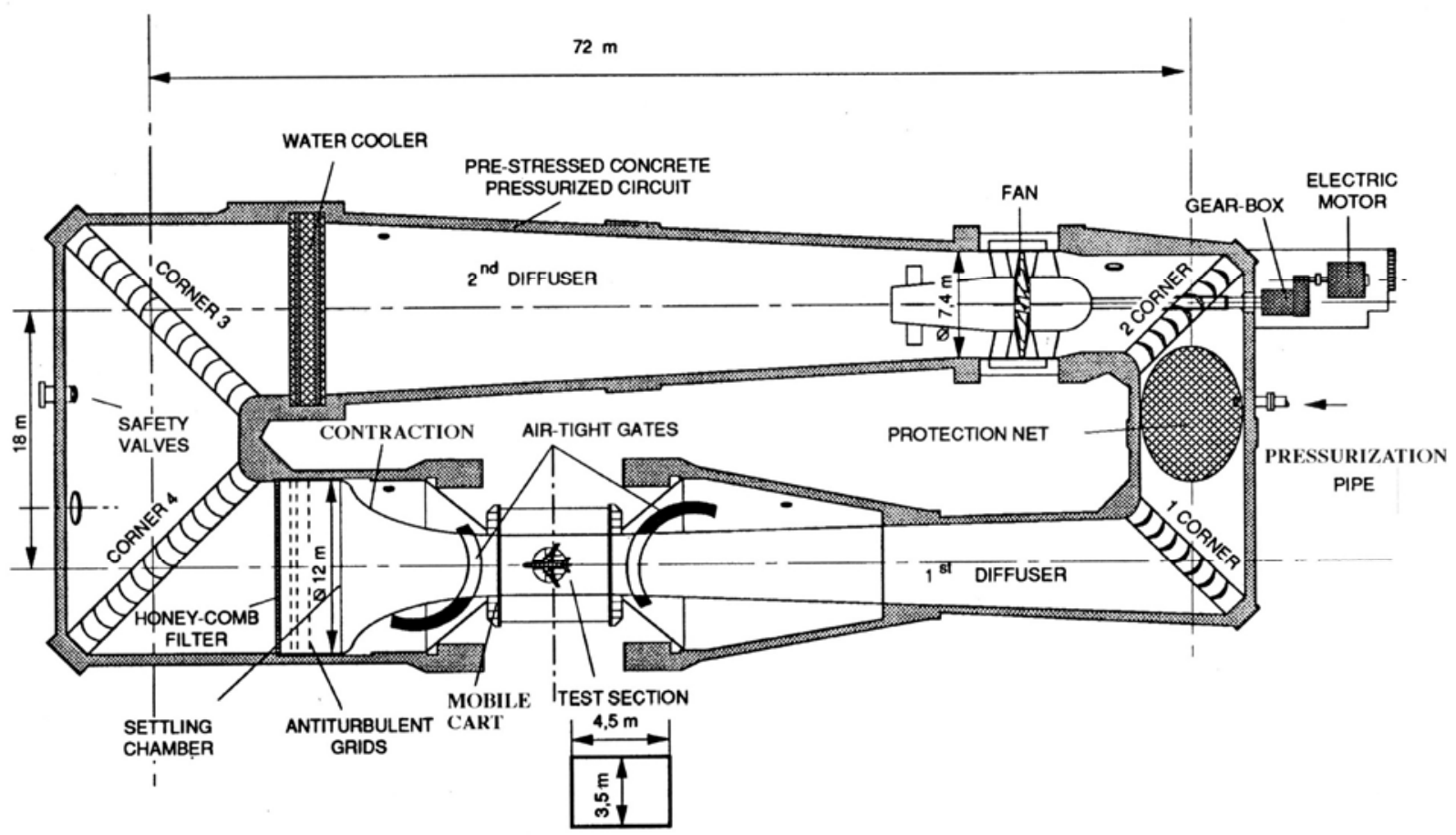

Figure 1. Schematic of the ONERA F1 Pressurized Wind Tunnel

The 72-inch (1828.8-mm) chord NACA 23012 airfoil model was mounted vertically in the test section, as shown in figure 2. The model span was 137.48 inches (3492 mm) and was mounted in the floor force balance. Small gaps between the bottom of the model and the test section floor, as well as the top of the model and the test section ceiling, were maintained so as not to cause mechanical hysteresis in the force-balance measurements. The model had a main chordwise row of 72 pressure taps located at $43 \%$ span measured from the test section floor. In addition, there was a row of 20 taps oriented spanwise at $x / c=0.70$ on the upper surface. The model was designed and built with full-span removable, interchangeable leading-edge sections. The baseline leading edge had the clean NACA 23012 profile, while the alternate leading edge had a truncated nose geometry. The latter design facilitated mounting of the runback-ridge ice-casting simulation. Accommodations were also made in the pressure tapping to allow for rapid connection of pressure instrumentation in the cast ice shapes. Also shown in figure 2 is the wake rake located one chord length downstream of the model trailing edge. The wake rake had 100 stagnation pressure probes spaced 0.79 -inch $(20-\mathrm{mm})$ apart and was located at a fixed spanwise station at $57 \%$ span above the test section floor. 


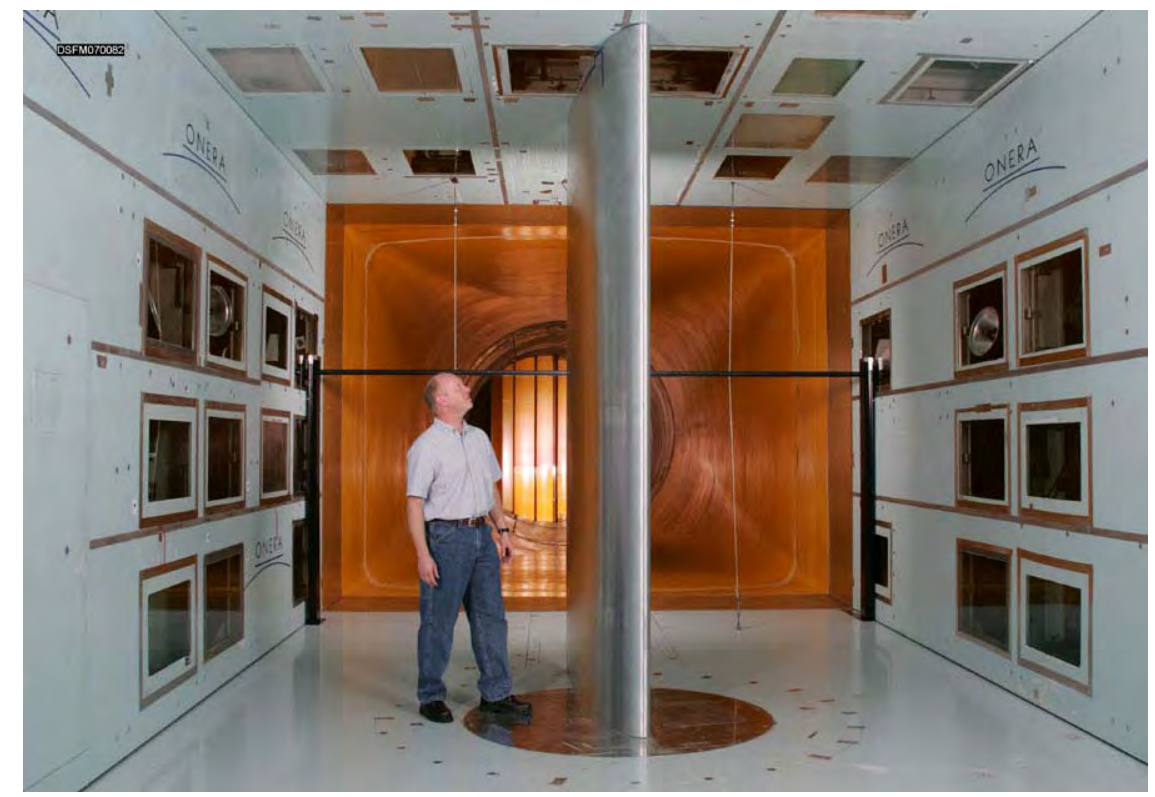

Figure 2. Photograph of the Full-Scale NACA 23012 Airfoil Model Installed in ONERA F1 Wind Tunnel Test Section

Data acquisition runs were performed in angle of attack sweeps for increasing and then decreasing angle of attack at a constant sweep rate of $0.1 \% \mathrm{sec}$. Data were also acquired at fixed angles of attack for selected angles over the range of the sweep, and repeat runs were performed. The data shown in this report are for increasing angle of attack sweeps and have been averaged to the nearest $0.5^{\circ}$ in postprocessing. During the sweeps, data were acquired from analog transducers in the force balance and for tunnel conditions. The model surface, test section sidewall, and wake rake pressures were acquired using an electronically scanned pressure system. The acquisition of these data was synchronized in time corresponding to the angle of attack sweep rate. Lift and pitching-moment coefficients were calculated from the force balance and from the integration of the surface pressure measurements. Good agreement between the integrated-pressure data and the force-balance data were obtained. In this report, the lift and pitching-moment data reported for the clean configuration were obtained from the surface pressures, while the data reported for the iced configuration were obtained from the force balance. Since the stall of the iced-airfoil configuration was characterized by unsteady flow, the available signal conditioning for the force-balance data allowed for more effective filtering of these unsteady effects. The drag coefficient was calculated from the wake pressures using standard momentum-deficit methods; these values are reported in this report for all configurations. The performance coefficients were corrected for wind tunnel wall effects using the methods of Allen and Vincenti [15]. The angle of attack sweeps were performed for a large range of Reynolds numbers and Mach numbers, as shown in table 1. The matrix was designed to isolate the independent effects of these parameters. Therefore, Reynolds number variations were performed at Mach numbers of 0.10 and 0.20 , while a Mach number variation was performed at a nominal Reynolds number of $12.2 \times 10^{6}$. 
Table 1. Matrix of Reynolds and Mach Number Conditions

\begin{tabular}{|c|c|c|c|}
\hline \multirow{2}{*}{$\begin{array}{c}\text { Reynolds } \\
\text { Number }\end{array}$} & \multicolumn{3}{|c|}{ Mach Number } \\
\cline { 2 - 4 } & 0.10 & 0.20 & 0.28 \\
\hline $4.7 \times 10^{6}$ & $\mathrm{X}$ & & \\
\hline $8.8 \times 10^{6}$ & $\mathrm{X}$ & $\mathrm{X}$ & \\
\hline $12.2 \times 10^{6}$ & $\mathrm{X}$ & $\mathrm{X}$ & $\mathrm{X}$ \\
\hline $16.0 \times 10^{6}$ & & $\mathrm{X}$ & \\
\hline
\end{tabular}

The experimental uncertainty in the performance coefficients was estimated using the methods of Kline and McClintock [16] and Coleman and Steele [17] for 20:1 odds. Table 2 lists these uncertainties for both integrated-pressure and force-balance measurements, before the wall corrections were applied. The values were calculated based upon the clean model configuration at $R e=8.1 \times 10^{6}$ and $M=0.20$. The absolute uncertainties in table 2 are inversely proportional to the dynamic pressure (except for $\alpha$ ). This condition was selected because it corresponds to the average dynamic pressure over the range of conditions (table 1). Therefore, conditions having lower dynamic pressure would have slightly larger uncertainties, while conditions with higher dynamic pressure would have slightly lower uncertainties. All uncertainties were acceptable for the purposes of this investigation. The relative uncertainty in $C_{m}$ (both pressure and balance) seems large for this example because of the small reference value. For cases where the $C_{m}$ values were larger, e.g., in the iced-airfoil case, the absolute uncertainty would be similar, therefore resulting in a lower relative uncertainty. This is also the case for the uncertainty in drag coefficient. Finally, several repeat runs were performed for both clean and iced configurations and these run-to-run variations in the coefficients were much smaller than the uncertainties listed in table 2.

Table 2. Estimated Experimental Uncertainties for Measurements in the ONERA F1 Wind Tunnel

\begin{tabular}{|l|l|l|c|}
\hline $\begin{array}{c}\text { Aerodynamic } \\
\text { Quantity }\end{array}$ & $\begin{array}{c}\text { Reference } \\
\text { Value } \\
\text { (degrees) }\end{array}$ & $\begin{array}{c}\text { Absolute } \\
\text { Uncertainty } \\
\text { (degrees) }\end{array}$ & $\begin{array}{c}\text { Relative } \\
\text { Uncertainty } \\
(\%)\end{array}$ \\
\hline$\alpha$ & 8.01 & \pm 0.02 & \pm 0.25 \\
\hline$C_{l}$ Balance & 1.095 & \pm 0.010 & \pm 0.93 \\
\hline$C_{m}$ Balance & -0.0144 & \pm 0.00071 & \pm 4.9 \\
\hline$C_{p}$ & -1.057 & \pm 0.032 & \pm 3.05 \\
\hline$C_{l}$ Pressure & 1.096 & \pm 0.0070 & \pm 0.64 \\
\hline$C_{m}$ Pressure & -0.0148 & \pm 0.0024 & \pm 16.5 \\
\hline$C_{d}$ Wake & 0.0086 & \pm 0.00048 & \pm 5.5 \\
\hline
\end{tabular}




\subsection{UNIVERSITY OF ILLINOIS WIND TUNNEL AND MODEL.}

The subscale aerodynamic testing was conducted in the University of Illinois subsonic, lowturbulence, open-return wind tunnel, which had a 33.63-inch (853-mm) high, 48-inch (1219-mm) wide, and 96-inch (2438-mm) long test section. The tests were performed on an aluminum NACA 23012 airfoil model with a chord length of 18 inches $(457.2 \mathrm{~mm})$ and a span of 33.563 inches $(852.5 \mathrm{~mm})$. The model had a primary chordwise row of 73 pressure taps located at 51\% span. Lift and pitching-moment coefficient data were acquired from a force balance and by integration of airfoil surface pressures measured by an electronically scanned pressure system. Excellent agreement between these methods was obtained for the clean model configuration. For the iced configurations, the ice simulations used in this study did not have pressure taps. This resulted in minor disagreement in the integrated coefficients with the force balance. Therefore, the lift and pitching-moment data shown in this report were obtained from the force balance. Using standard momentum-deficit methods, the drag coefficient was computed from total pressure measurements collected by a traversable wake rake. This wake rake is shown installed behind the airfoil model in figure 3. Busch [18] and Blumenthal [19] describe the experimental set-up in greater detail. Experimental uncertainties were calculated using the methods of Kline and McClintock [16] and Coleman and Steele [17], and a summary of these uncertainties is given in table 3 . While the relative uncertainty of $C_{m}$ appears to be large because the reference value is small, the absolute uncertainty is reasonable. The angle of attack, lift, pitching-moment, and drag coefficients were corrected for wind tunnel wall boundary effects using the methods of Allen and Vincenti [15]. All data were collected at a Reynolds number of $1.8 \times 10^{6}$ and a Mach number of 0.18 , unless noted otherwise.

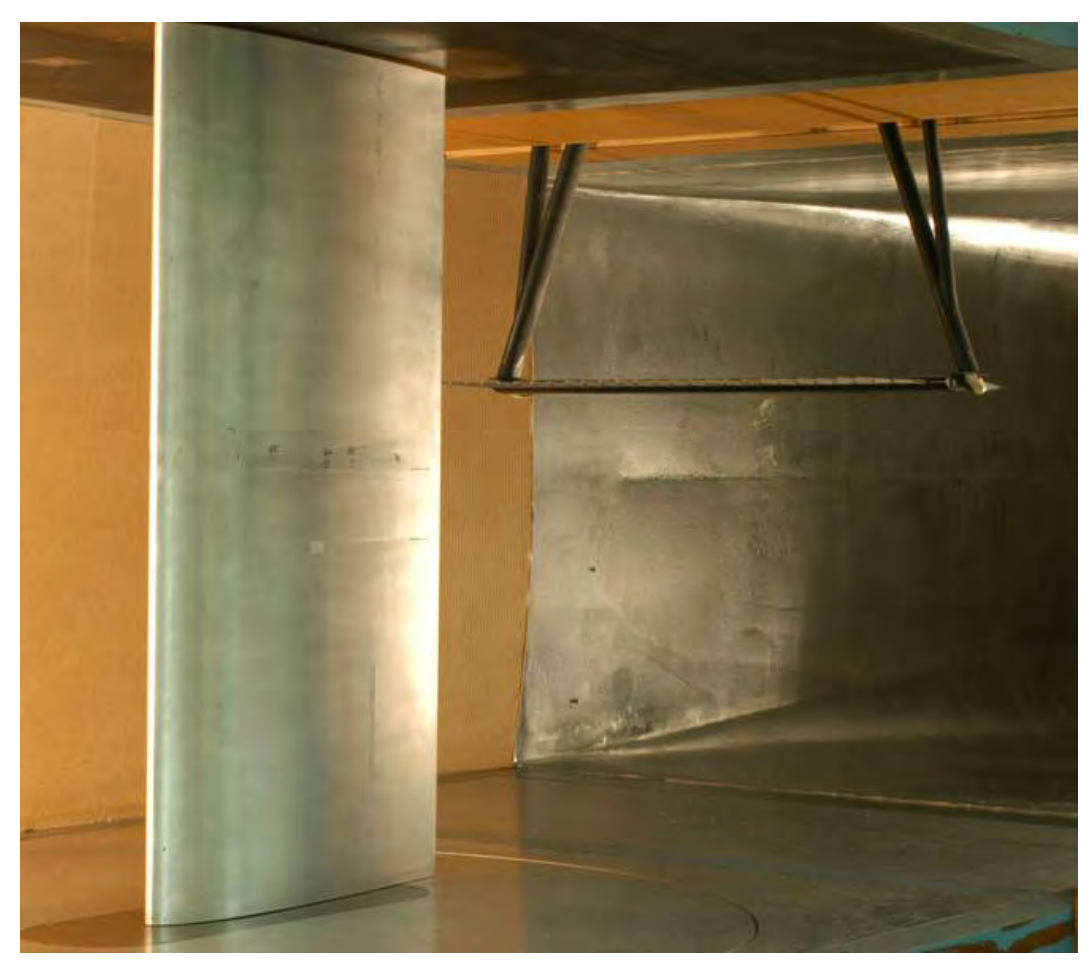

Figure 3. Photograph of Subscale NACA 23012 Airfoil Model Installed in University of Illinois Wind Tunnel Test Section 
Table 3. Estimated Experimental Uncertainties for Measurements in the University of Illinois Wind Tunnel

\begin{tabular}{|l|l|l|c|}
\hline $\begin{array}{c}\text { Aerodynamic } \\
\text { Quantity }\end{array}$ & $\begin{array}{c}\text { Reference } \\
\text { Value } \\
\text { (degrees) }\end{array}$ & $\begin{array}{c}\text { Absolute } \\
\text { Uncertainty } \\
\text { (degrees) }\end{array}$ & $\begin{array}{c}\text { Relative } \\
\text { Uncertainty } \\
(\%)\end{array}$ \\
\hline$\alpha$ & 4.13 & \pm 0.02 & \pm 0.48 \\
\hline$C_{l}$ Balance & 0.556 & \pm 0.00086 & \pm 0.16 \\
\hline$C_{m}$ Balance & -0.0015 & \pm 0.00027 & \pm 17.4 \\
\hline$C_{p}$ & -0.962 & \pm 0.0045 & \pm 0.47 \\
\hline$C_{d}$ Wake & 0.0071 & \pm 0.00014 & \pm 1.9 \\
\hline
\end{tabular}

\subsection{FULL-SCALE MODEL ICE-SHAPE SIMULATION METHODS.}

The runback ice simulation tested on the full-scale model was a high-fidelity ice casting that was adapted from an earlier icing test conducted at the NASA IRT [20 and 21]. The runback ice accretion designated NG0671 was considered to be representative of flight in holding conditions for a full-scale aircraft equipped with a bleed-air, thermal ice-protection system. A mold and casting of this ice accretion were produced and pictures of the completed casting are shown in figure 4. A tracing of the runback ice accretion NG0662 from a companion run is shown in figure 5. All test conditions between NG0671 and NG0662 were identical, so the tracing shown in figure 5 represents a cross section of the runback ice accretion shown in figure 4 . Due to the operation of the thermal ice protection system, the leading edge is completely free of ice up to about $x / c=0.13$ on the upper surface and $x / c=0.15$ on the lower surface. Characteristics of the upper-surface ridge are that it was continuous along the span, had significant chordwise extent, and had some variation in height along the span. In contrast, the lower-surface ridge had a significant amount of spanwise variation with the largest ice elements being isolated, threedimensional features, instead of forming a continuous ridge. As discussed in section 1, the threedimensional nature of this type of accretion requires a high-fidelity simulation to obtain accurate aerodynamic results.

Since the IRT model used to generate ice accretion NG0671 was not identical to the full-scale NACA 23012 model used for the aerodynamic tests, the ice casting was modified to the latter geometry. The castings of the ice ridges shown in figure 4 were extracted from the IRT model geometry and applied to a leading-edge section corresponding to the full-scale NACA 23012 aerodynamic model. This representation of the runback ice accretion was then used to generate a series of ice-casting sections used for the aerodynamic tests through a process described in detail by Broeren, et al. [22]. The completed installation is shown in figure 6. A tracing of the completed ice shape on the NACA 23012 airfoil leading edge along with the pressure tap locations is given in figure 7 . This tracing does not show the height profile of the large, isolated ice elements on the lower surface due to a spanwise shift in the tracing location from that shown in figure 5. The tracing in figure 7 only extends to $x / c=0.20$, since this was the physical limit of the ice-casting section applied to the full-scale NACA 23012 aerodynamic model. Any runback ice downstream of $x / c=0.20$ was not present in the casting simulation used for the aerodynamic 
tests. As shown in figure 5, this amounted to a very small amount of ice and was considered negligible in terms of its attendant aerodynamic effect.
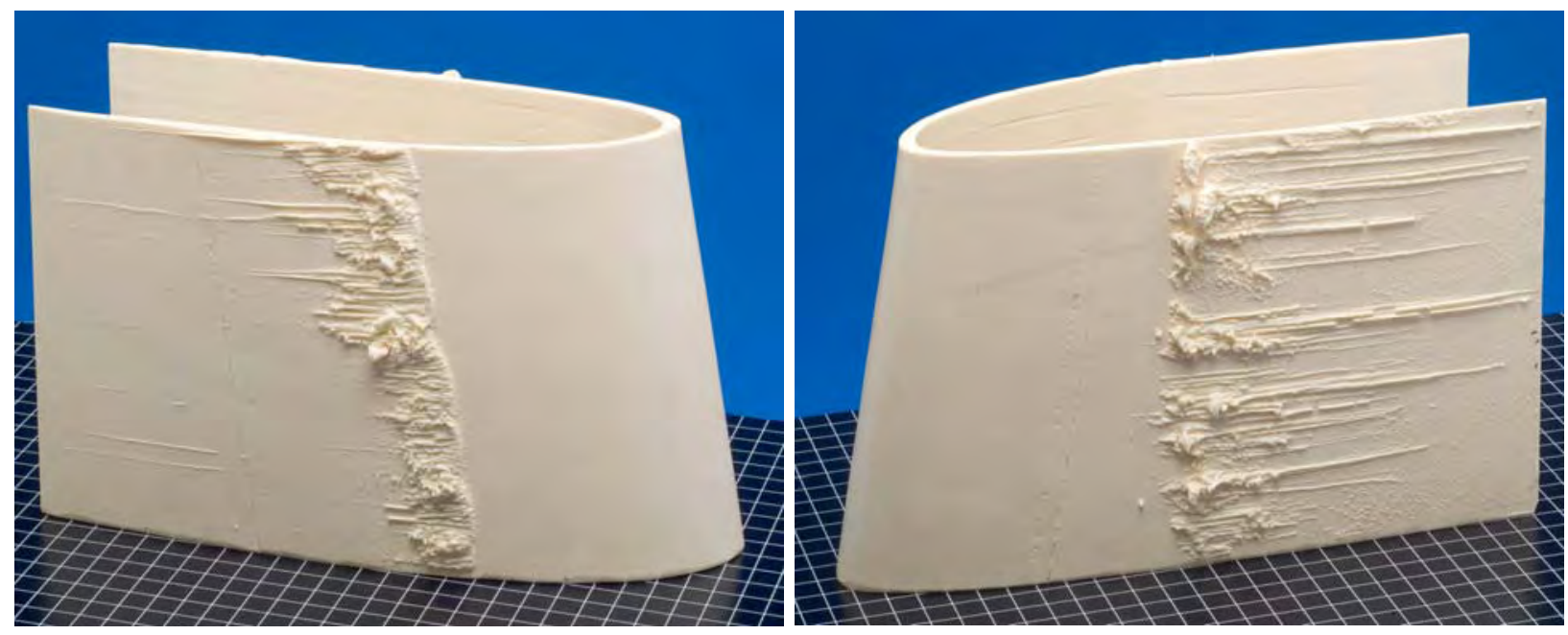

Figure 4. Photograph of NG0671 Runback Ice Accretion Casting (Left-Upper-Surface Ridge, Right_Lower-Surface Ridge)

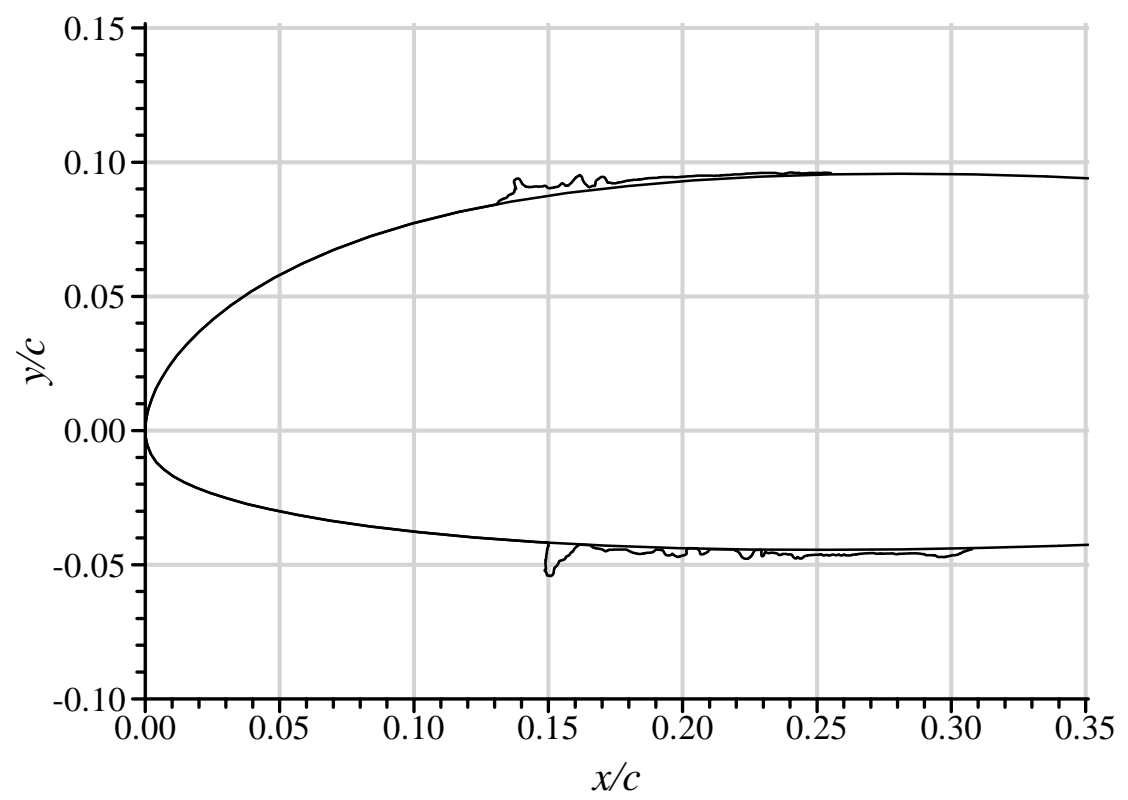

Figure 5. Tracing of NG0662 Runback Ice Accretion Formed at Conditions Identical to the NG0671 Casting Shown in Figure 4 

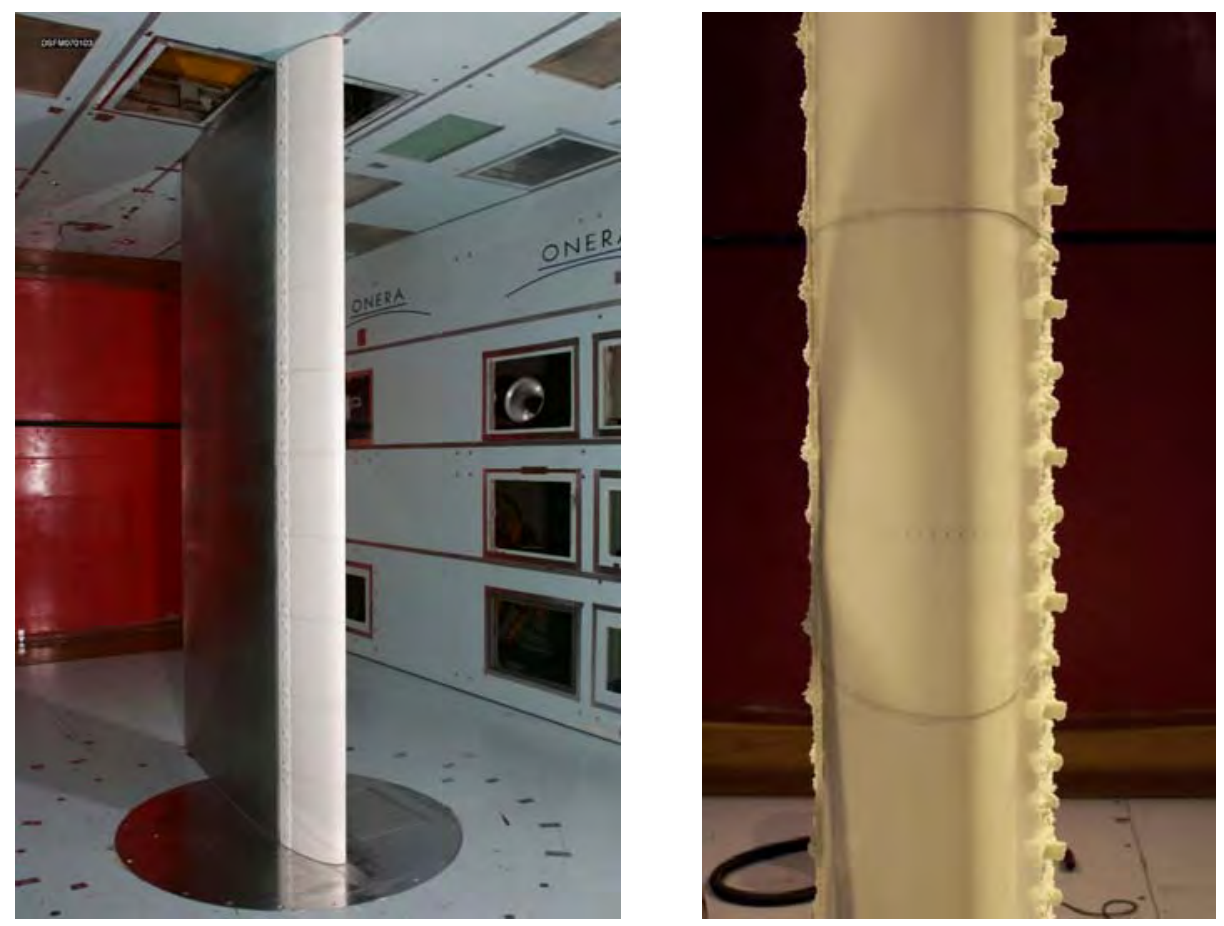

Figure 6. Completed Installation of Runback Ridge Simulation NG0671 on the Leading Edge of the Full-Scale NACA 23012 Model

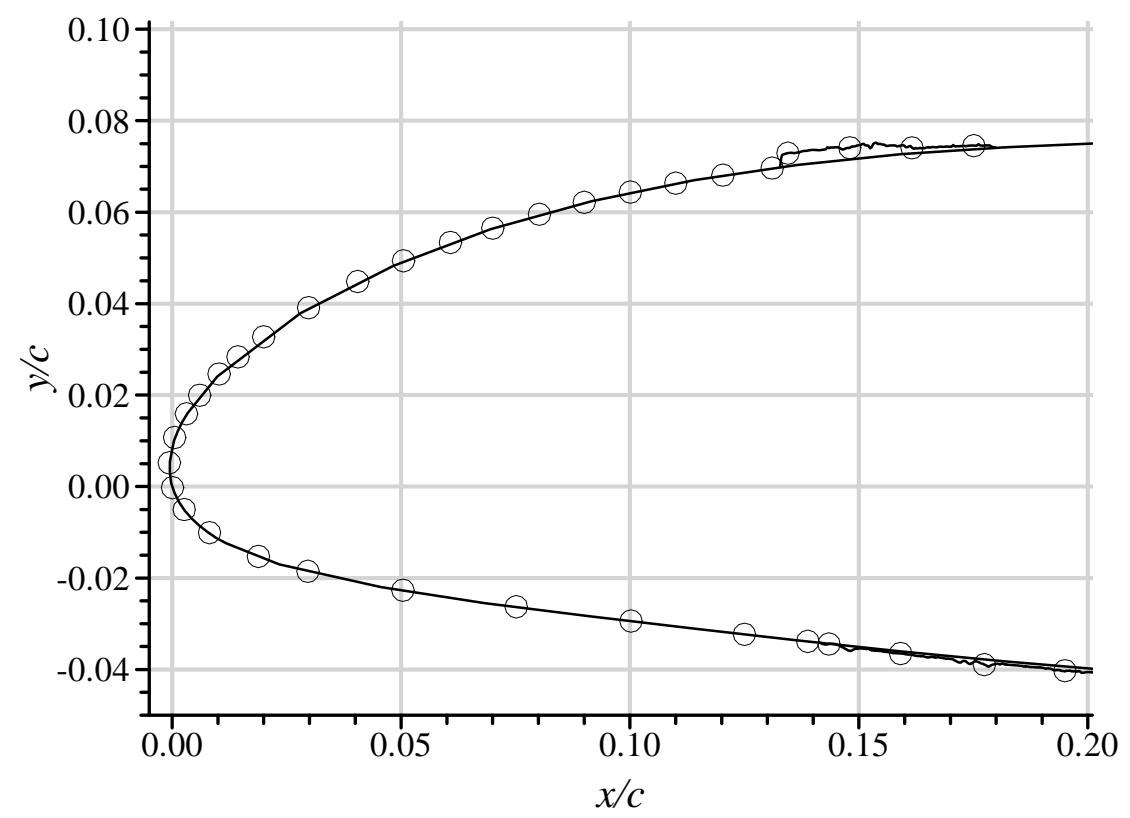

Figure 7. Tracing of Runback Ice Casting NG0671 on the NACA 23012 Leading Edge (Open circles indicate pressure orifice locations.)

\subsection{SUBSCALE MODEL ICE-SHAPE SIMULATION METHODS.}

The subscale NACA 23012 model was tested with several variations of NG0671 runback-ridge simulations. These simulations were constructed using commercial off-the-shelf materials 
because the runback accretion was too small (upper surface) and too three-dimensional (lower surface) to model with rapid-prototyping methods such as stereolithography. A "build-up" approach was employed in which individual ice features were added to the upper and lower surface incrementally. This approach yielded an understanding of the aerodynamic effects of individual simulation features. The simulation methods and terminology follow those established in closely related research [1, 12, 18, 23, and 24]. Table 4 summarizes the individual features that were combined to simulate the NG0671 runback-ridge ice accretion. The "SG" notation refers to "simple geometry" which, in this case, means that the runback ridge was simulated with a two-dimensional rectangular shape. This was attached to the model surface at $x / c=0.13$, identical to the full-scale ice accretion location. The height of the upper-surface ridge was $k / c=0.0028$, identical to the maximum height of the upper-surface tracing in figure 7 . This was a geometric scaling of the traced cross-section. The actual ice accretion did have some variation in height along the span that was not modeled with the simple-geometry simulation. Following the "build-up" approach, carborundum roughness elements with height $k / c=0.0008$ were applied to the top of the simple-geometry ridge (SG+R-US in table 4) to model roughness and height variations in the actual accretion. These simulations are shown in figure 8. Analogous simple-geometry simulations were also developed and tested on the model lower surface. In this case, using a two-dimensional simulation was difficult to define due to the highly three-dimensional nature of the lower-surface ice accretion, thus it required engineering judgment. The height $k / c=0.0039$ was selected for the lower-surface SG ridge based upon matching the combined frontal area of large isolated ice elements. The sensitivity of the lowersurface ice accretion simulation was determined by developing a higher-fidelity, threedimensional simulation. The individual isolated ice elements were geometrically scaled and attached to a thin substrate on the lower surface. In addition, simulated frozen rivulets were also modeled. These features are shown in figure 9. Aerodynamic tests were performed with various combinations of upper- and lower-surface simulations to quantify their effects.

Table 4. Summary of Runback-Ridge Ice Simulations

\begin{tabular}{|c|l|}
\hline Simulation & \multicolumn{1}{|c|}{ Description } \\
\hline SG-US & $\begin{array}{l}\text { Rectangular ridge on upper surface, with height } k / c=0.0028 \text { at } x / c=0.13, \\
\text { chordwise extent } \Delta x / c=0.047\end{array}$ \\
\hline SG-LS & $\begin{array}{l}\text { Rectangular ridge on lower surface, with height } k / c=0.0039 \text { at } x / c=0.15, \\
\text { chordwise extent } \Delta x / c=0.042\end{array}$ \\
\hline SG+R-US & Roughness elements, height $k / c=0.0008$ applied to upper-surface ridge \\
\hline SG+R-LS & Roughness elements, height $k / c=0.0008$ applied to lower-surface ridge \\
\hline SG+Riv-US & $\begin{array}{l}\text { Simulated frozen rivulets, height } k / c=0.0017 \text { and density of } 18 \text { rivulets per } \\
\text { inch-span applied to upper-surface ridge }\end{array}$ \\
\hline 3D-LS & $\begin{array}{l}\text { Three-dimensional simulation of lower-surface ridge ice elements, height } \\
\text { varied between } k / c=0.0022 \text { and } 0.0106\end{array}$ \\
\hline 3D+Riv-LS & $\begin{array}{l}\text { Simulated frozen rivulets, height } k / c=0.0017 \text { and density of } 18 \text { rivulets per } \\
\text { inch-span applied to three-dimensional, lower-surface ice simulation }\end{array}$ \\
\hline
\end{tabular}



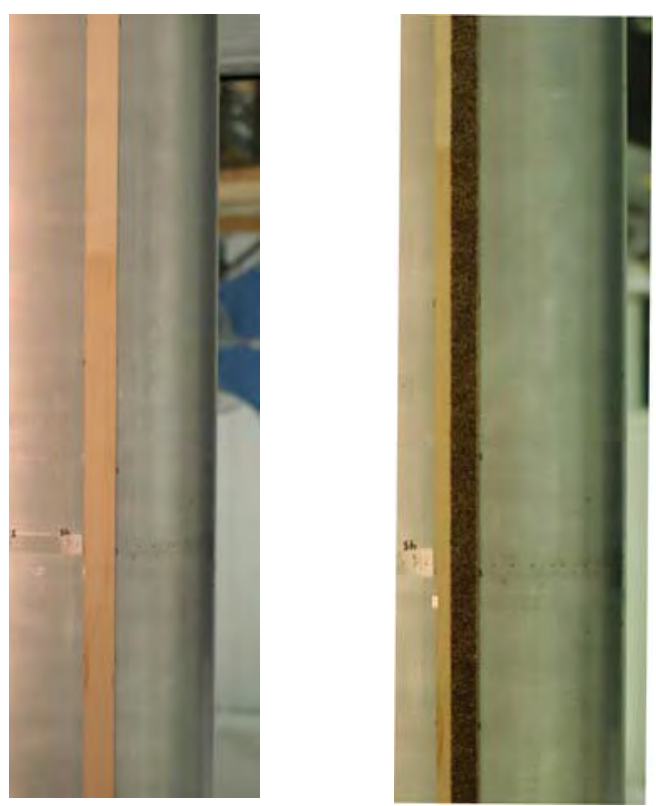

Figure 8. Photographs of Subscale Model Upper-Surface Ridge Simulations (Left—Simple-Geometry Ridge (SG-US), Right—Simple-Geometry Ridge With Applied Roughness (SG+R-US))
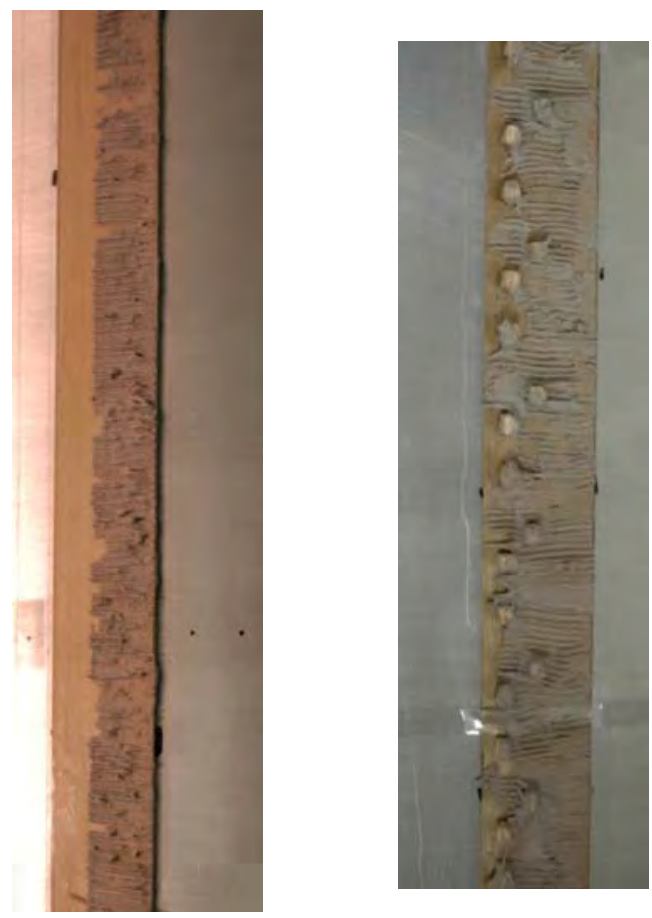

Figure 9. Photographs of Subscale Model Ridge Simulations (Left-Upper-Surface, SimpleGeometry Ridge With Simulated Frozen Rivulets (SG+Riv-US), Right-Lower-Surface, ThreeDimensional Simulation With Simulated Frozen Rivulets (3D+Riv-LS)) 


\section{RESULTS AND DISCUSSION.}

\subsection{FULL-SCALE RESULTS.}

The effect of the high-fidelity NG0671 runback ice simulation on the performance of the NACA 23012 airfoil is illustrated in figure 10 for $R e=16.0 \times 10^{6}$ and $M=0.20$. Broeren, et al. [22] provide a detailed analysis of the clean NACA 23012 performance data establishing its validity compared to archival and computational data. For this condition, the maximum lift coefficient of the clean NACA 23012 was 1.82 at an angle of attack of $18.1^{\circ}$. The abrupt loss of lift at stall is indicative of leading-edge stall. For this stall type, boundary-layer separation occurs near the leading edge without subsequent reattachment, resulting in separated flow over the airfoil and the significant decrease in lift [25]. The pitching-moment coefficient was nearly independent of angle of attack up until about $\alpha=10^{\circ}$. The effect of the NG0671 ice simulation was to reduce the lift-curve slope and maximum lift coefficient. The ice simulation produced angle of attack dependence of the pitching-moment coefficient at much lower angle of attack, commencing at approximately $\alpha=4^{\circ}$. The presence of the runback ice simulation resulted in a greater than twofold increase in drag coefficient over the angle of attack range shown in figure 10. The maximum lift coefficient was reduced to 1.51 at $\alpha_{\text {stall }}=15.0^{\circ}$ in addition to a change in the character of the stall. Analysis of the surface pressure data and mini-tuft flow visualization indicated significant trailing-edge separation at maximum lift coefficient. However, the decrease in lift for $\alpha>16^{\circ}$ appeared to be due to flow separation on the entire upper surface originating from the leading edge or from the spanwise ridge. Therefore, the iced-airfoil stall type was classified as a combination of trailing-edge and leading-edge stall.

While these are significant performance effects, they are not as severe as those found for other ice shapes tested on the full-scale NACA 23012 model. Plotted in figure 10 for comparison are data for three other ice-casting configurations taken from Broeren, et al. [22]. Tracings of these ice shapes are shown in figure 11. EG1162 and EG1164 were leading-edge ice shapes, while EG1159 was a tall spanwise ridge. The performance data show the increasing severity for each configuration in terms of reduced $\mathrm{C}_{1, \max }$ and $\alpha_{\text {stall, increased pitching-moment slope, and }}$ increased drag. It is interesting to note that the streamwise ice shape EG1162 resulted in lower drag than the runback ridge NG0671 up to $\alpha \approx 9.5^{\circ}$, as the airfoil with the EG1162 ice shape began to stall. As described in detail by Broeren, et al. [22], the stall of this configuration maintained the character of the abrupt, leading-edge stall type of the clean airfoil. For the EG1164 and EG1159 configurations, the aerodynamics were governed primarily by a large upper-surface separation bubble resulting from the ice accretion. The separation bubble grew larger with increasing angle of attack precipitating the stall at a much lower angle of attack than for the clean airfoil. This combined with the physical size of the ice shape also contributed to the large increase in drag from the clean airfoil configuration. 

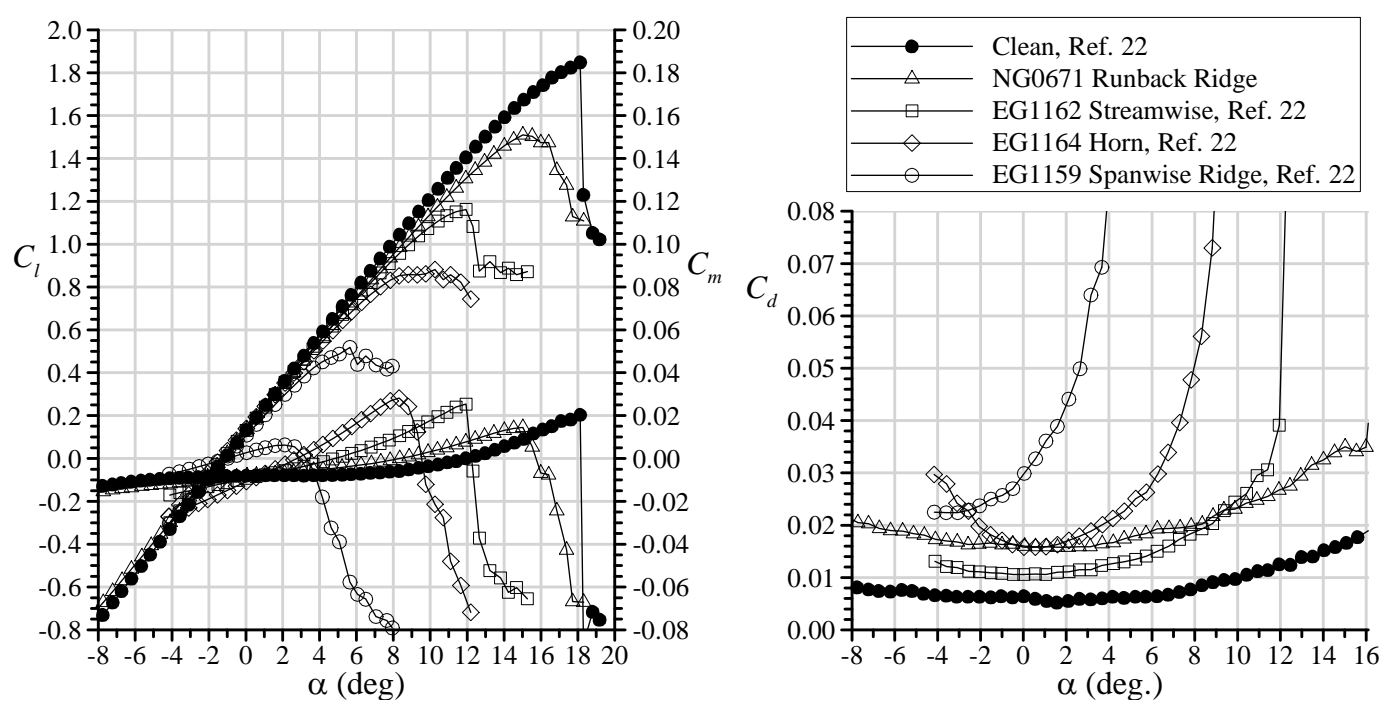

Figure 10. Comparison of Clean and Iced NACA 23012 Airfoil Performance for Various High-Fidelity, Ice-Casting Simulations at $R e=16.0 \times 10^{6}$ and $M=0.20$
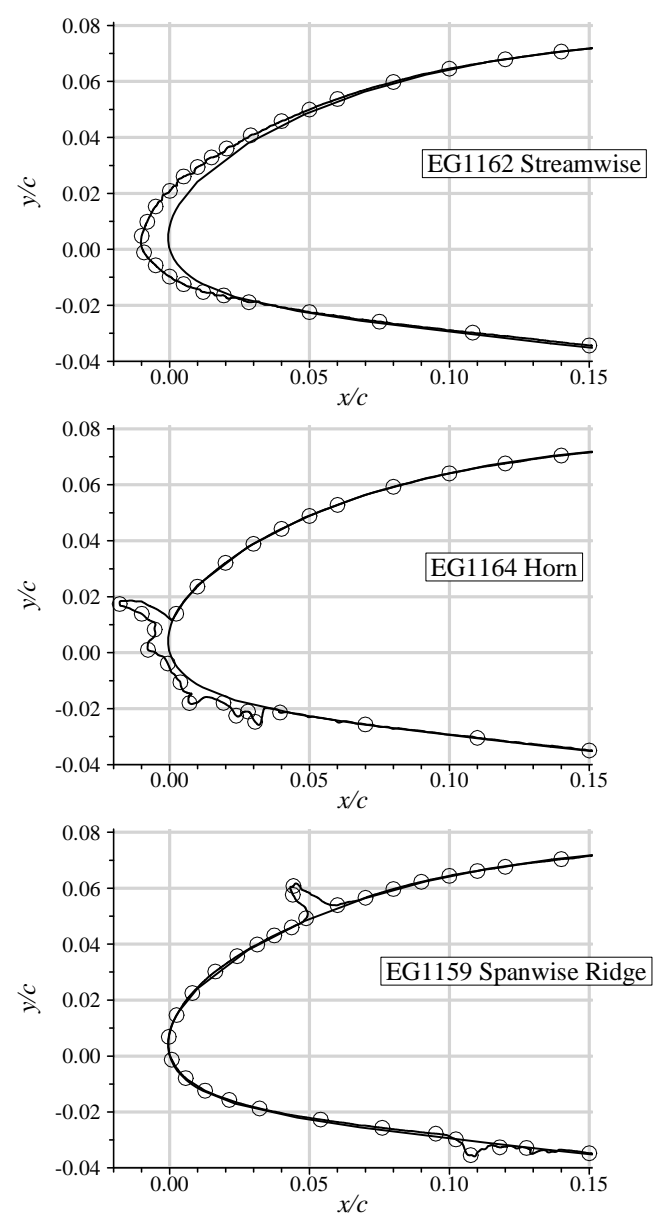

Figure 11. Various Ice-casting simulations Tested by Broeren, et al. on the Full-Scale NACA 23012 Airfoil Model (Open circles indicate pressure orifice locations.) 
The aerodynamic effect of these ice shapes is compared further in terms of surface pressure distribution in figure 12. Here, the data are split into two separate plots for clarity. First, consider the comparison of the NG0671 runback ridge, EG1162 streamwise ice, and clean airfoil configurations. At this angle of attack, there was very little difference in surface pressure between the clean airfoil and the EG1162 configuration. The streamwise ice shape, being conformal to the NACA 23012 leading edge, does not result in large-scale boundary-layer separation or other significant redistribution of static pressure for this angle of attack. This explains, in part, the minimal increase in drag from the clean configuration relative to the other iced configurations for this angle of attack. The surface pressure distribution of the NG0671 configuration clearly reveals the effect of the ice shape on both the upper and lower surface. At this positive angle of attack, the effect on the upper surface was much more pronounced. There was a large change in pressure, from $C_{p}=-0.4$ to -2.7 at the forward face of the ridge. These measurements capture the flow deceleration immediately forward of the ridge followed by the flow acceleration over the top of the ridge. This was then followed by a rapid pressure recovery with the static pressure reconforming to the clean airfoil values of $x / c>0.18$. Surface-oil flow visualization was performed for this case by applying a thin film of oil treated with fluorescent dye to the surface of the model. The model angle of attack was set and the tunnel was operated allowing the oil to flow on the surface until a steady-state condition was achieved. These visualizations revealed the presence of a small separation bubble immediately aft of the ridge with subsequent reattachment within only a few percent chord. An important characteristic to note is that the pressure distribution was only altered from the clean configuration in the immediate vicinity of the runback ridge. Furthermore, the effect on the surface pressure was somewhat symmetric in that the effect on the integrated lift and pitching moment was small. The effect on pitching moment was also mitigated by the location of the ridge being close to the moment center at $x / c=0.25$. Clearly the drag coefficient was increased by the forward face of the ridge and resulting separation. This explains, in part, why the drag coefficient was higher than for the EG1162 configuration. There was also additional drag due to the ice elements on the lower surface of the NG0671 runback-ridge configuration.

Also plotted in figure 12 are surface pressure distributions for the EG1164 and EG1159 icedairfoil configurations. For these cases, there was a large deviation from the clean airfoil owing to the large extent of separated flow. For the EG1164 shape, the flow separated near the tip of the horn resulting in the region of nearly constant pressure from $x / c=-0.02$ to 0.03 on the upper surface. There was significant pressure recovery downstream of $x / c=0.03$, but $C_{p}$ did not approach that of the clean airfoil until $x / c=0.20$. For the EG1159 spanwise ridge shape, the separated flow region was much larger as indicated by the region of nearly constant pressure from $x / c=0.04$ to 0.30 on the upper surface. This region was followed by a very gradual pressure recovery. Surface-oil flow visualization performed at this angle of attack indicated a time-averaged separation bubble reattachment zone from $x / c=0.64$ to 0.68 . The pressure data for this case also reveal the large effect of the lower-surface ridge. It also had a small separation bubble associated with it. The large extent of separated flow for the EG1159 configuration is consistent with the large degradation in the performance coefficients in figure 10.

The angle of attack evolution of surface pressure distribution is shown in detail in figure 13 for the NG0671 configuration. The iced-airfoil pressure distribution shown in figure 10 for $\alpha=4.2^{\circ}$ was maintained for all angles of attack prior to stall. That is, there was only a significant 
deviation from the clean pressure distribution in the immediate vicinity of the upper and lower surface ridges. The comparison plot at $\alpha=16.0^{\circ}$ shows the deviation of the iced-airfoil $C_{p}$ toward the trailing-edge, indicating the presence of boundary-layer separation. Increasing the angle of attack to $17.4^{\circ}$ resulted in complete separation of the upper-surface boundary layer, as reflected in figure 13.
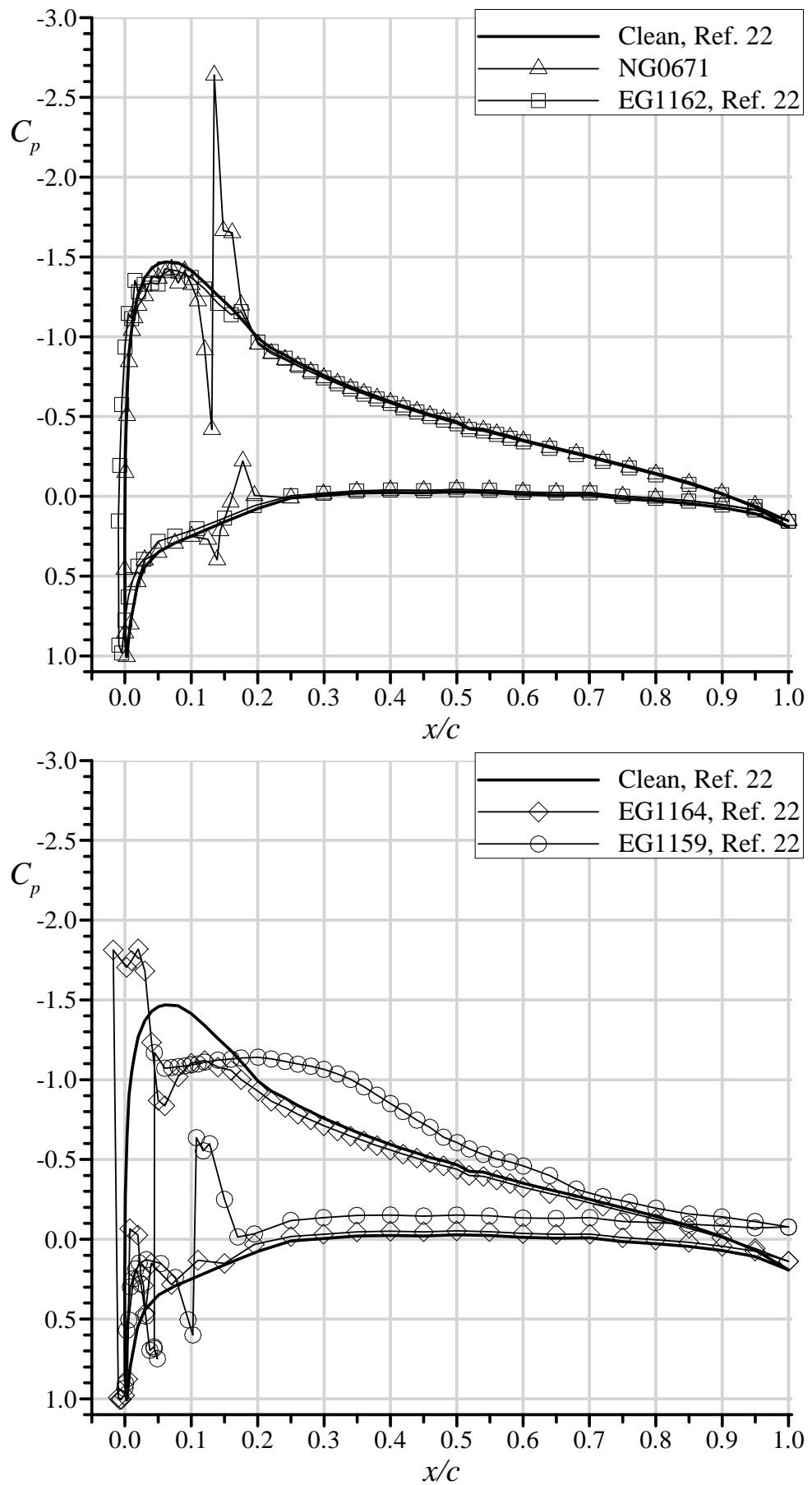

Figure 12. Comparison of Clean and Iced NACA 23012 Airfoil Pressure Distribution for Various High-Fidelity, Ice-Casting Simulations at $\alpha=4.2^{\circ}, R e=16.0 \times 10^{6}$, and $M=0.20$ 

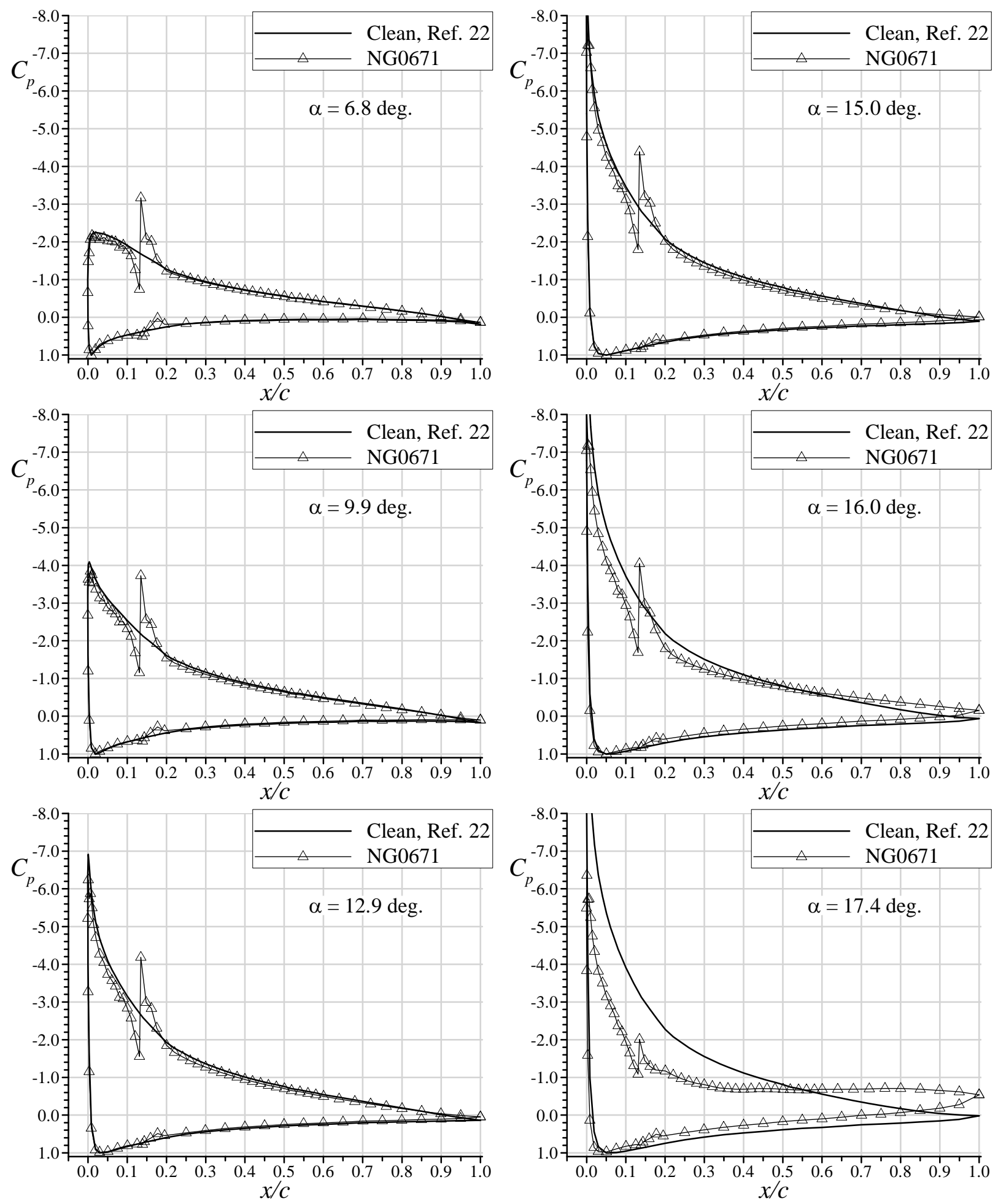

Figure 13. Comparison of Clean and Iced NACA 23012 Airfoil Pressure Distribution for Various Angles of Attack at $R e=16.0 \times 10^{6}$ and $M=0.20$

The pressurization capability of the ONERA F1 wind tunnel was fully exploited to establish the effects of Reynolds and Mach number on the performance of the NACA 23012 airfoil with the 
NG0671 runback ridge. In general, changes in Reynolds number from $4.7 \times 10^{6}$ to $12.2 \times 10^{6}$ at $M=0.10$ and from $8.9 \times 10^{6}$ to $16.0 \times 10^{6}$ at $M=0.20$ had very little effect on the iced-airfoil performance, as illustrated in figures 14 and 15. Changes in Mach number from 0.10 to 0.28 at $R e=12.2 \times 10^{6}$ had slightly more effect on the iced-airfoil performance, with a small increase in drag coefficient over this range, as shown in figure 16. These results are consistent with previous aerodynamic studies of iced airfoils [8, 22, and 26-29].
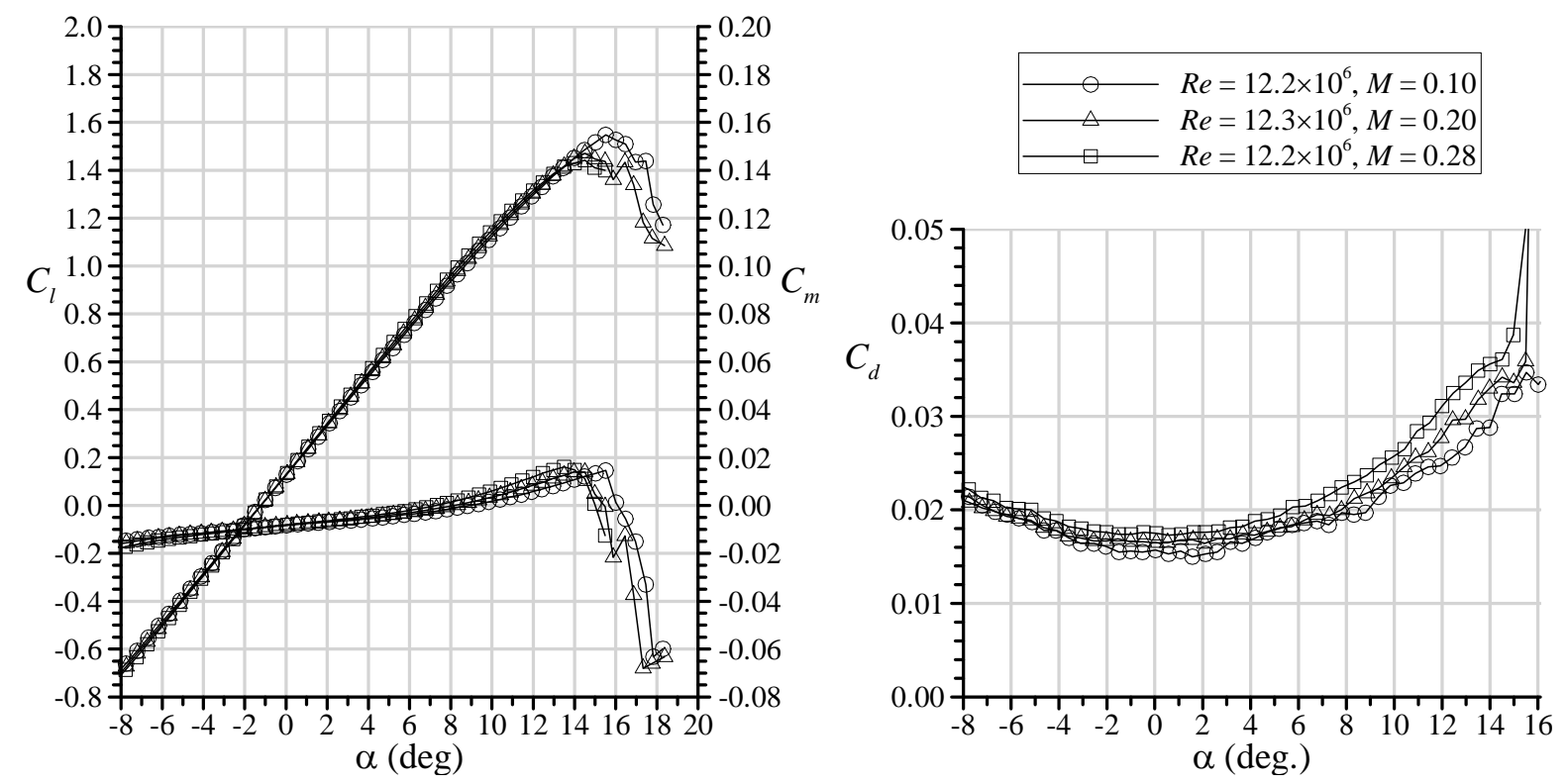

Figure 14. Effect of Reynolds Number on the Performance of the NACA 23012 Airfoil With the NG0671 Ice Casting at $M=0.10$
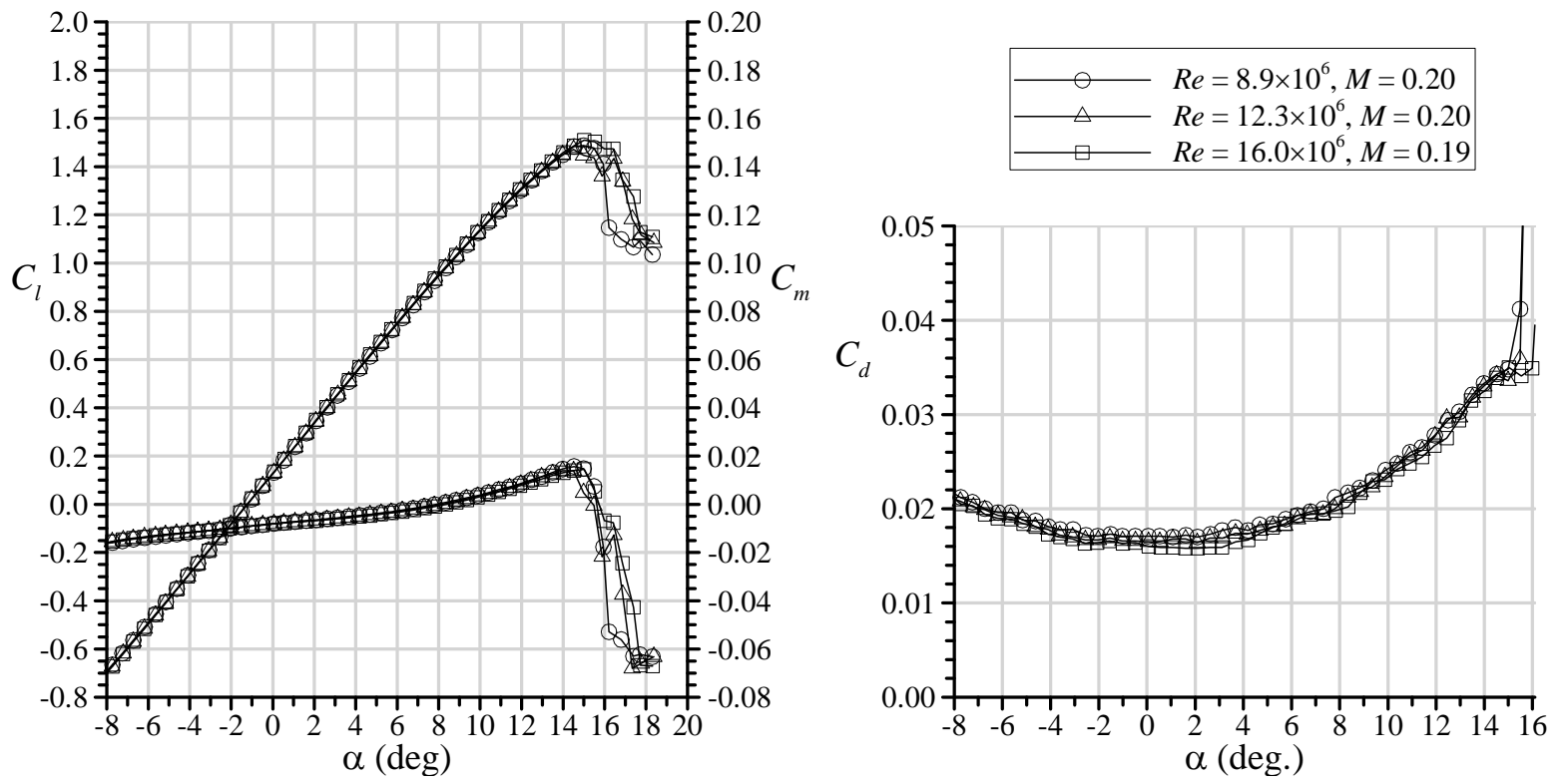

Figure 15. Effect of Reynolds Number on the Performance of the NACA 23012 Airfoil With the NG0671 Ice Casting at $M=0.20$ 

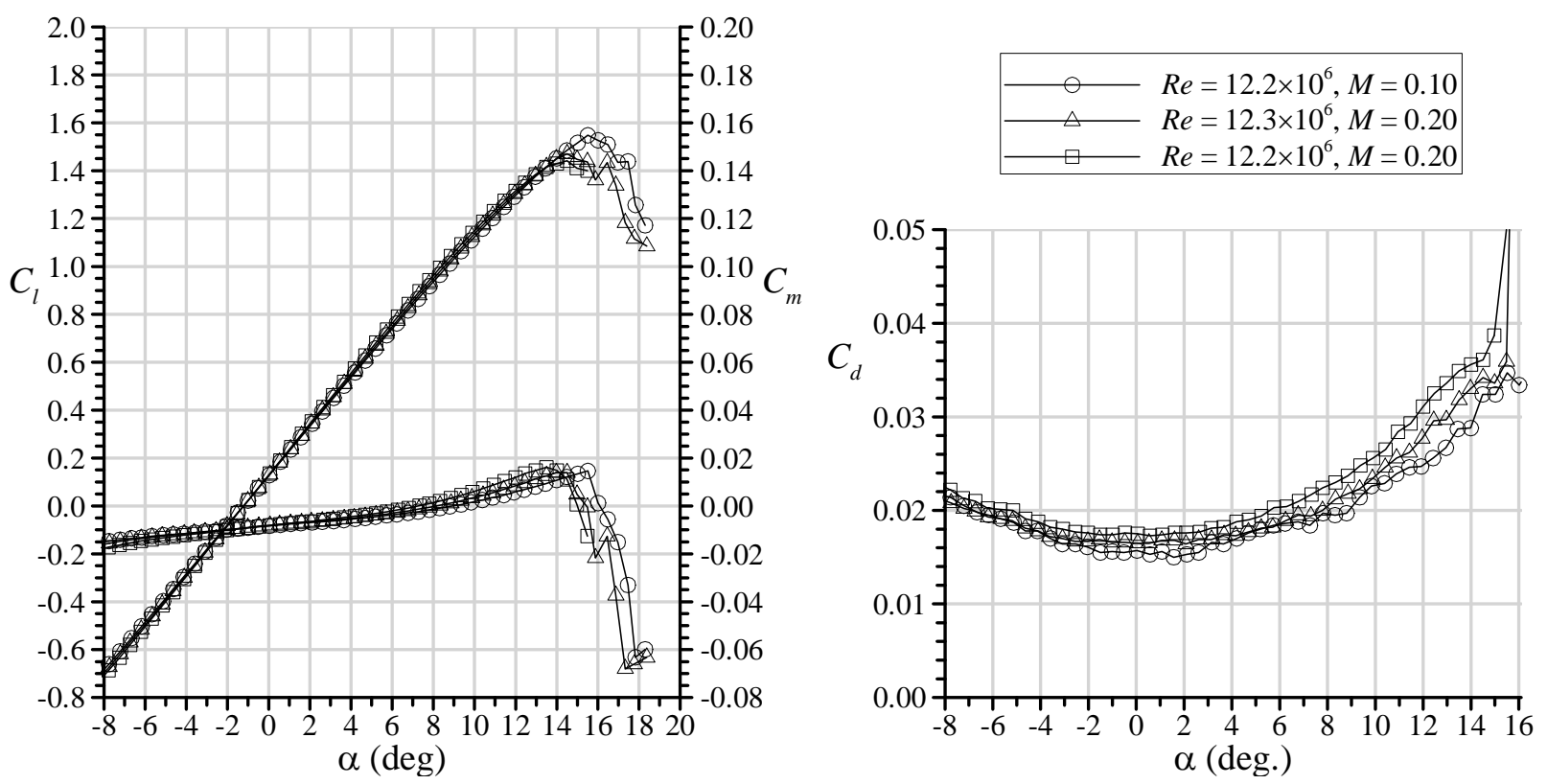

Figure 16. Effect of Mach Number on the Performance of the NACA 23012 Airfoil With the NG0671 Ice Casting at $R e=12.2 \times 10^{6}$

The effect of Reynolds and Mach number on iced-airfoil performance can be further summarized through analysis of the maximum lift coefficient. This parameter is plotted for various configurations against Reynolds number in figure 17. These data, along with the data from Broeren, et al. [22], were all acquired in the ONERA F1 wind tunnel. The data from Broeren, et al. [8] were acquired in the NASA Langley Low-Turbulence Pressure Tunnel. Since both facilities were pressurized wind tunnels, the Mach number was held constant at the values specified. The comparison in $\mathrm{C}_{l, \max }$ for the clean NACA 23012 airfoil is considered to be good, given the potential differences in models, model scale, installation, facilities, as well as experimental uncertainty. The $\mathrm{C}_{\mathrm{l}, \max }$ increased from 1.50 at $R e=2.0 \times 10^{6}, M=0.12$ to 1.88 at $R e=12.3 \times 10^{6}, M=0.10$. As shown in figure 17, there was much less Reynolds number dependence of $\mathrm{C}_{\mathrm{l}, \max }$ for the iced-airfoil configurations. There was some variation in $\mathrm{C}_{\mathrm{l}, \max }$ with Reynolds number for the NG0671 runback ridge, but no clear trend. More data are needed to establish what Reynolds number dependence there may be, particularly for $R e<4.7 \times 10^{6}$. Included for comparison to the NG0671 runback ridge are the four ice shapes from figures 10-12 and a forward-facing, quarter-round spanwise ridge ice shape. The quarter-round shape had height $k / c=0.0139$ and was tested at two chordwise locations on the airfoil $(x / c=0.02$ and 0.10). The data for the leading-edge ice shapes EG1162 and EG1164 show virtually no change in $\mathrm{C}_{1, \max }$ over the $R e$ range tested. The data for the EG1159 configuration indicate a small decrease in $\mathrm{C}_{l, \text { max }}$ for $R e=4.6 \times 10^{6}$ to $12.2 \times 10^{6}$ at $M=0.10$. The quarter-round cases show even less variation with no significant change in $C_{l, \max }$ versus $R e$ from $2.0 \times 10^{6}$ to $10.5 \times 10^{6}$ for these tall spanwise ridge shapes. The data in figure 17 show that Mach number is an equally, if not more, significant parameter for spanwise ridge ice shapes.

The effect of Mach number on maximum lift coefficient is summarized in figure 18 for the same iced-airfoil configurations. The data show good agreement for the values of $\mathrm{C}_{\mathrm{l}, \max }$ on the clean 
airfoil, particularly for $M>0.20$. Of the iced-airfoil configurations, the spanwise ridges had the most dependence on Mach number. For the NG0671 runback ridge, the Mach number dependence was similar to, if not more than, the clean airfoil. The $\mathrm{C}_{1, \max }$ for the airfoil with the tall spanwise ridge shapes (EG1159 and quarter round) also shows some Mach number dependence. Iced-airfoil Mach number effects have been addressed in other studies [2 and 30].

Aside from the Reynolds and Mach number effects, a more significant effect for the tall ridge shapes is the upper-surface location of the ridges. Close inspection of figure 11 yields a ridge height, $k / c=0.013$ at $x / c=0.05$ in chordwise location. This is very similar in height to the $k / c=0.0139$ quarter-round shape data in figures 17 and 18. Lee and Bragg [7] researched the impact of ridge location and airfoil type on aerodynamic performance degradation. They found that $\mathrm{C}_{1, \max }$ was a strong function of spanwise ridge location between $x / c=0.0$ and 0.10 for this airfoil. This explains why there is such a large difference in $\mathrm{C}_{\mathrm{l} \text {,max }}$ between the quarter-round shape at $x / c=0.02$ and 0.10 and why the data for the EG1159 ridge fit neatly in between.
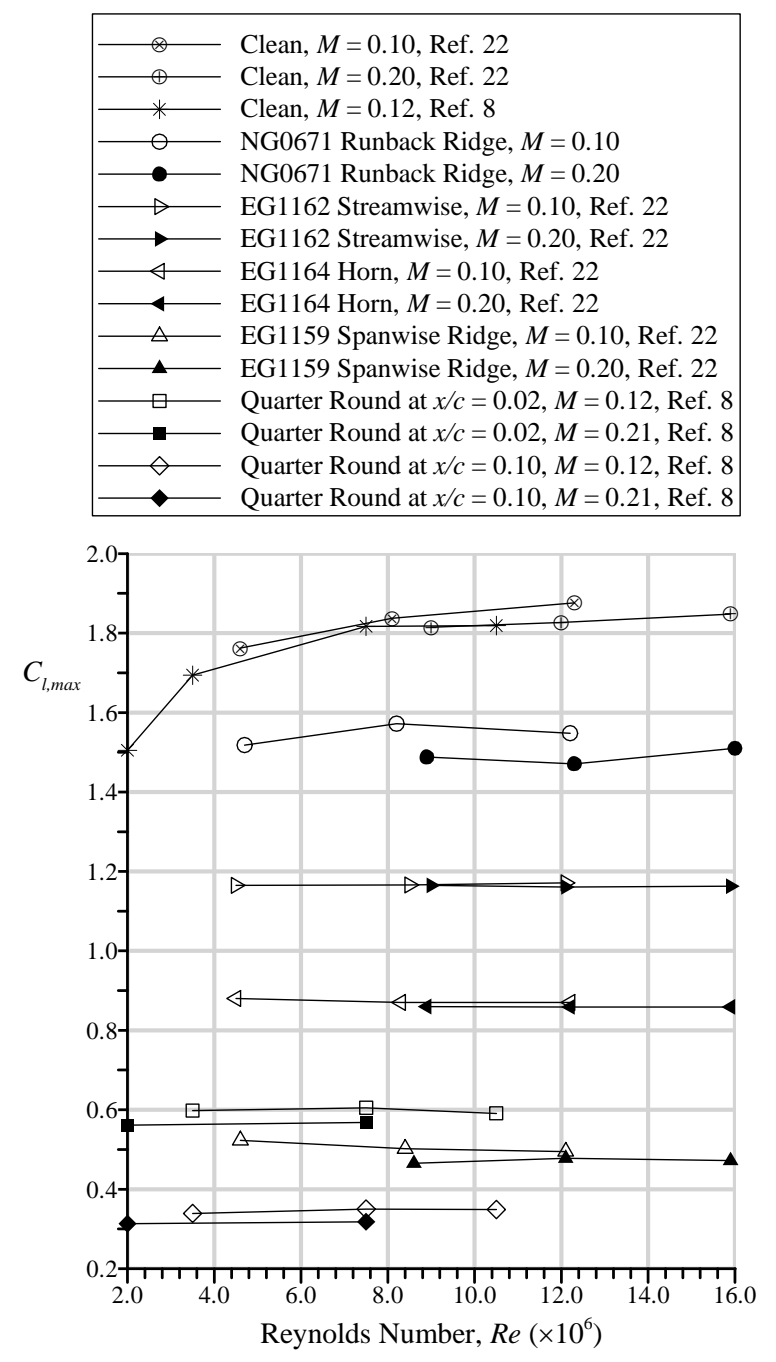

Figure 17. Effect of Reynolds Number on Maximum Lift Coefficient for the NACA 23012 Airfoil for Clean and Iced Configurations 

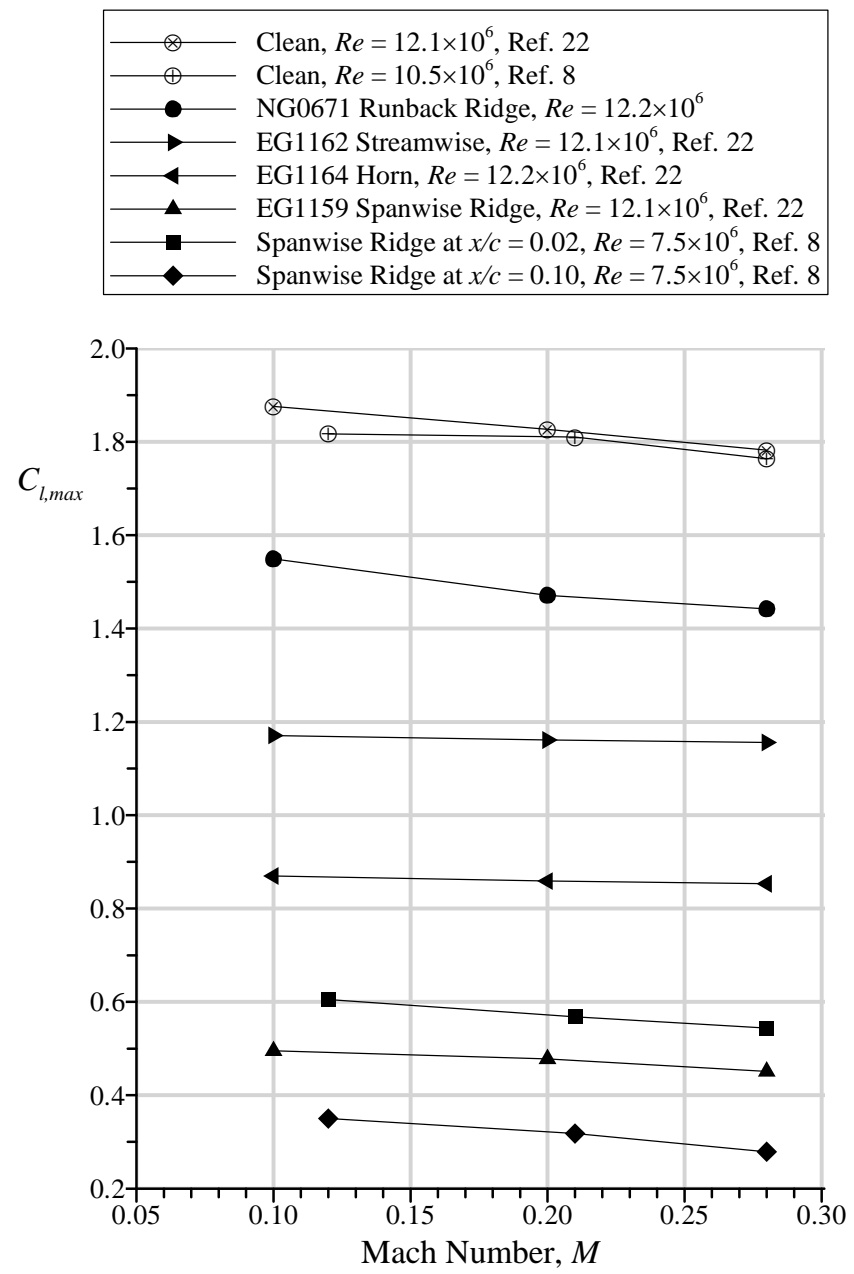

Figure 18. Effect of Mach Number on Maximum Lift Coefficient for the NACA 23012 Airfoil for Clean and Iced Configurations

\subsection{SUBSCALE SIMULATION OF RUNBACK RIDGE AERODYNAMICS.}

Simulating the aerodynamics of a runback ridge on a quarter-scale model at low Reynolds number can be challenging because of Reynolds number effects for the clean airfoil. This conundrum is illustrated in figure 19, which shows that the iced-airfoil configuration at $R e=16.0 \times 10^{6}$ and $M=0.20$ had a slightly higher lift-curve slope, $\mathrm{C}_{\mathrm{l} \text {,max }}$, and $\alpha_{\text {stall }}$ than the clean airfoil at $R e=1.8 \times 10^{6}$ and $M=0.18$. The iced-airfoil configuration also had slightly less dependence of $C_{m}$ on angle of attack. Only the drag coefficient was significantly different from the low Reynolds number clean configuration. These data may explain the apparent anomalies in previous subscale runback-ridge aerodynamic studies. For example, Calay, et al. [4] observed small increases in $\mathrm{C}_{\mathrm{l}, \max }$ and $\alpha_{\text {stall }}$ with a $k / c=0.0035$ simple-geometry ridge on a NACA 0012 airfoil at $R e=1.25 \times 10^{6}$ and $M=0.08$. Similarly, Papadakis and Gile-Laflin [5] also observed lift performance increases for simple-geometry ridges on a NACA $63_{\mathrm{A}}-213$ airfoil at $R e=2.0 \times 10^{6}$ and $M=0.17$. Whalen, et al. [9 and 10] and Lee, et al. [13] are further examples. As shown in figure 19, the decrease in maximum lift coefficient and stalling angle of attack for 
the clean airfoil from $R e=16.0 \times 10^{6}$ to $R e=1.8 \times 10^{6}$ was larger than the degradation due to the NG0671 ice-casting simulation at $R e=16.0 \times 10^{6}$. Therefore, subscale simulations of the NG0671 shape at low Reynolds number must result in a slight increase in maximum lift and stalling angle relative to the clean airfoil to simulate the aerodynamic effect at higher Reynolds number. In the current study, the challenge was to identify the accuracy to which the aerodynamics of the NG0671 runback ridge could be simulated on the quarter-scale model at low Reynolds number.

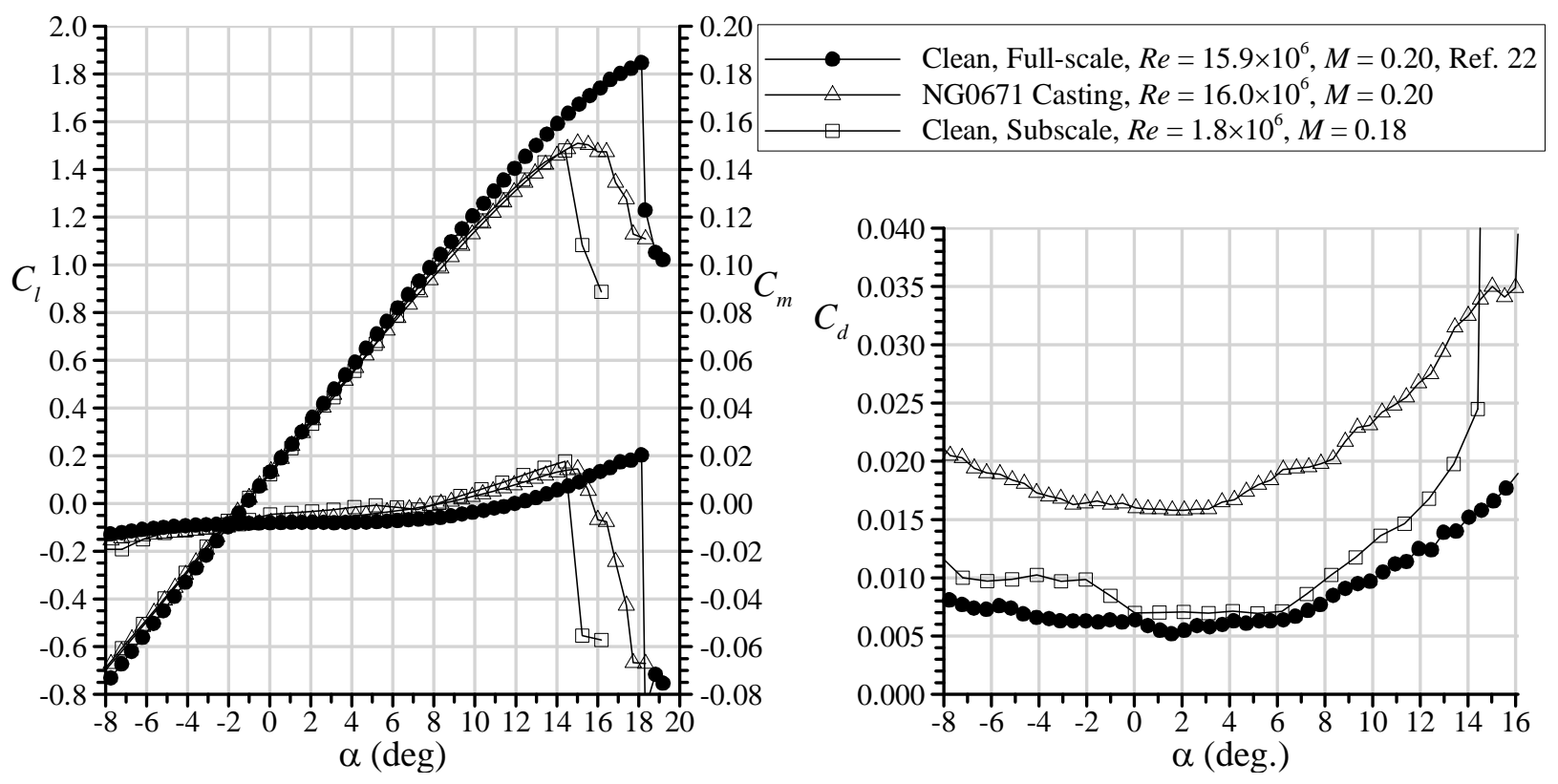

Figure 19. Comparison of $C_{l}, C_{m}$, and $C_{d}$ vs $\alpha$ for the Clean Subscale Model and the Full-Scale NG0671 Casting and Clean Configurations

The present approach employed simple-geometry ridge simulations in various configurations. The initial performance results are shown in figure 20 for three subscale configurations at $R e=1.8 \times 10^{6}$ and $M=0.18$ compared to the full-scale NG0671 ice-casting and clean configurations at $R e=16.0 \times 10^{6}$ and $M=0.20$. The data for the SG-US configuration show the effect of the $k / c=0.0028$ upper-surface, simple-geometry ridge. The lift-curve slope for this configuration was slightly lower than the airfoil with the NG0671 casting, but the $\mathrm{C}_{\mathrm{l} \text {,max }}$ value of 1.50 and $\alpha_{\text {stall }}$ value of $15.4^{\circ}$ compared very favorably with the full-scale data. The leading-edge stall characteristics of the clean airfoil persisted in the subscale iced-airfoil case in contrast to the full-scale casting simulation that had characteristics of trailing-edge stall. Despite the good comparison in $\mathrm{C}_{1, \max }$ and $\alpha_{\text {stall, }}$ the character of the iced-airfoil stall was not adequately simulated with the simple-geometry ridge on the upper surface. It is interesting to note, however, that the SG-US simulation slightly increased both $C_{l, \max }$ and $\alpha_{\text {stall }}$ relative to the clean airfoil values at the same Reynolds number and Mach number; thus acting like a low Reynolds number liftenhancement device. Figure 20 also shows that the SG-US subscale simulation caused a stronger dependence of the pitching-moment coefficient on angle of attack than for the full-scale, iced airfoil. The effect on drag coefficient was larger at higher angle of attack, since the SG-US simulation was located on the upper surface. The addition of the lower-surface ridge (SG-US \& SG-LS) improved the drag coefficient comparison while having very little effect on the stalling 
characteristics. This superposition of iced-airfoil effects has been observed in other studies of horn-type ice shapes [2 and 31] and spanwise ridge shapes [32]. Therefore, it was expected that the addition of the lower-surface ridge would primarily affect the drag, with little or no effect on lift and pitching moment at higher angle of attack.

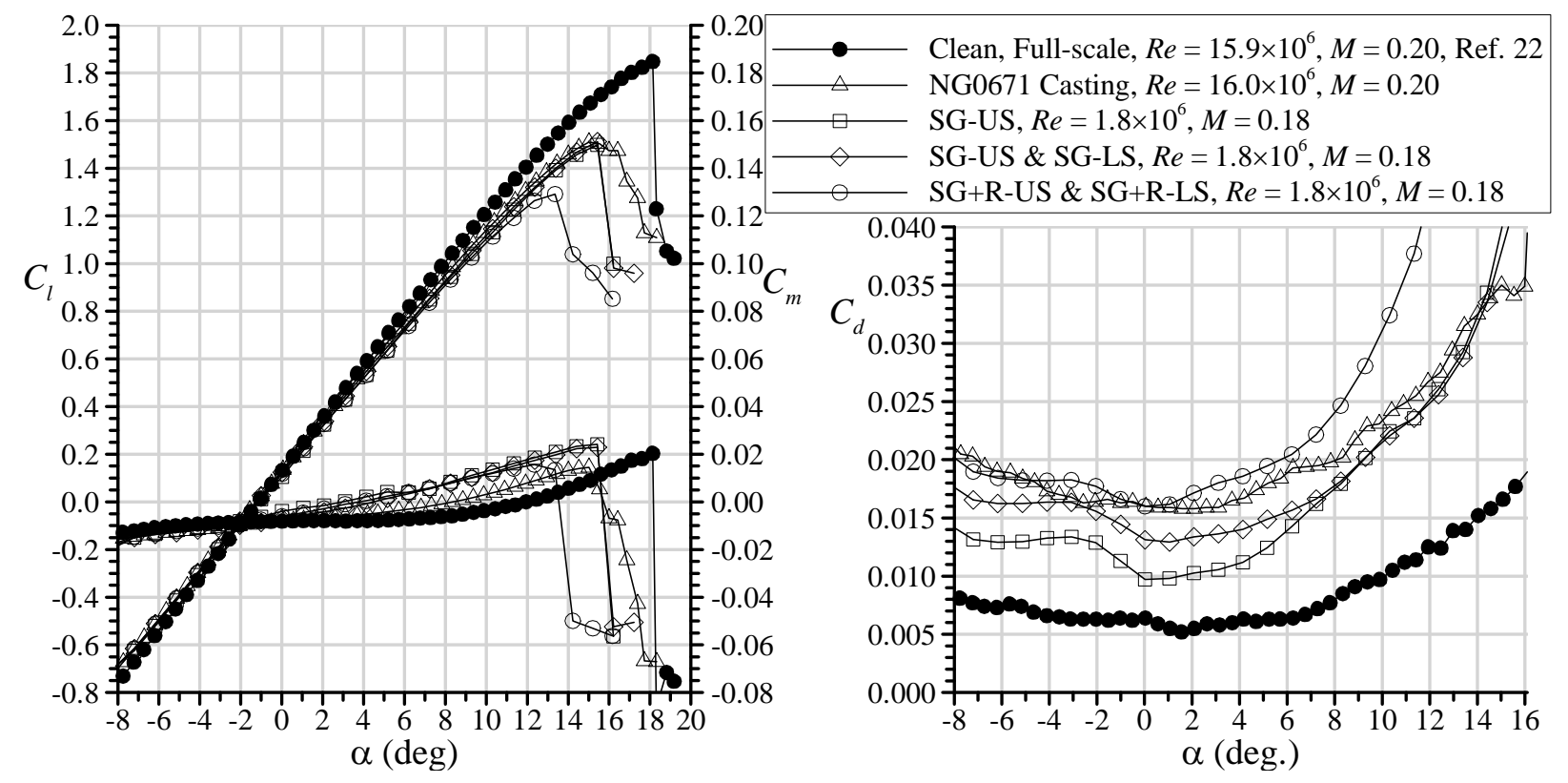

Figure 20. Comparison of $C_{l}, C_{m}$, and $C_{d}$ vs $\alpha$ for Various Subscale Runback-Ridge Simulations and the Full-Scale NG0671 Casting and Clean Configurations

The effect of added roughness was determined via carborundum grains with $k / c=0.0008$ applied to each upper- and lower-surface simple-geometry ridges. The lift data show that this had a very significant effect on the maximum lift coefficient and stalling angle of attack such that the comparison with the full-scale casting configuration was poor. These results are consistent with the conclusions of Calay, et al. [4] and Whalen, et al. [9], who noted that the stalling characteristics of the airfoil with simulated runback ridges can be very sensitive to the height or geometry of the ridge. As expected, the addition of the roughness on the lower-surface ridge increased the drag coefficient for this configuration at lower angle of attack, thus improving the drag comparison with the full-scale casting. However, the large deviations beginning at approximately $2^{\circ}$ were due to the roughness applied to the upper-surface ridge and were consistent with the lower maximum lift coefficient and stalling angle.

The differences in the aerodynamic effect of these simulations are further illustrated in the surface pressure distributions. Figure 21 compares the pressure coefficients for the upper- and lower-surface, simple-geometry ridges with and without applied roughness to the full-scale NG0671 casting and clean configurations at a matched angle of attack of $12.4^{\circ}$. The three runback-ridge simulations share some similarities. There were no significant differences between the clean and iced pressure distributions, except in the vicinity of the upper-surface ridge. For all iced configurations, the presence of the upper-surface ridge caused a small reduction in the magnitude of the suction peak and lower suction pressures downstream on the 
upper-surface relative to the clean airfoil. The pressure coefficients near the trailing edge, particularly for the subscale ice simulations, were also lower, possibility indicating local boundary-layer separation at this angle of attack. The pressure distribution for the full-scale NG0671 casting configuration compared very favorably with the upper- and lower-surface, simple-geometry ridge simulation (SG-US \& SG-LS). The large suction peak near the forward face of the ridge for the casting configuration was not measured for the subscale simulations since the subscale simulations were not instrumented with pressure taps. The favorable comparison between the pressure distributions for the NG0671 casting and the subscale simplegeometry ridges (without added roughness) further confirms that there is proper simulation of the aerodynamics. The pressure distribution for the simple-geometry ridges with added roughness shows a deviation in $C_{p}$ just downstream of $x / c=0.17$ on the upper surface. This deviation indicates the presence of a separation bubble downstream of the ridge with roughness. Since this separation bubble had a noticeable effect on the pressure distribution, it was likely larger than the separation bubble documented for the full-scale NG0671 configuration. This larger separation bubble contributed to the stall at lower angle of attack compared to the no-roughness case, as well as the increased drag at higher angle of attack.

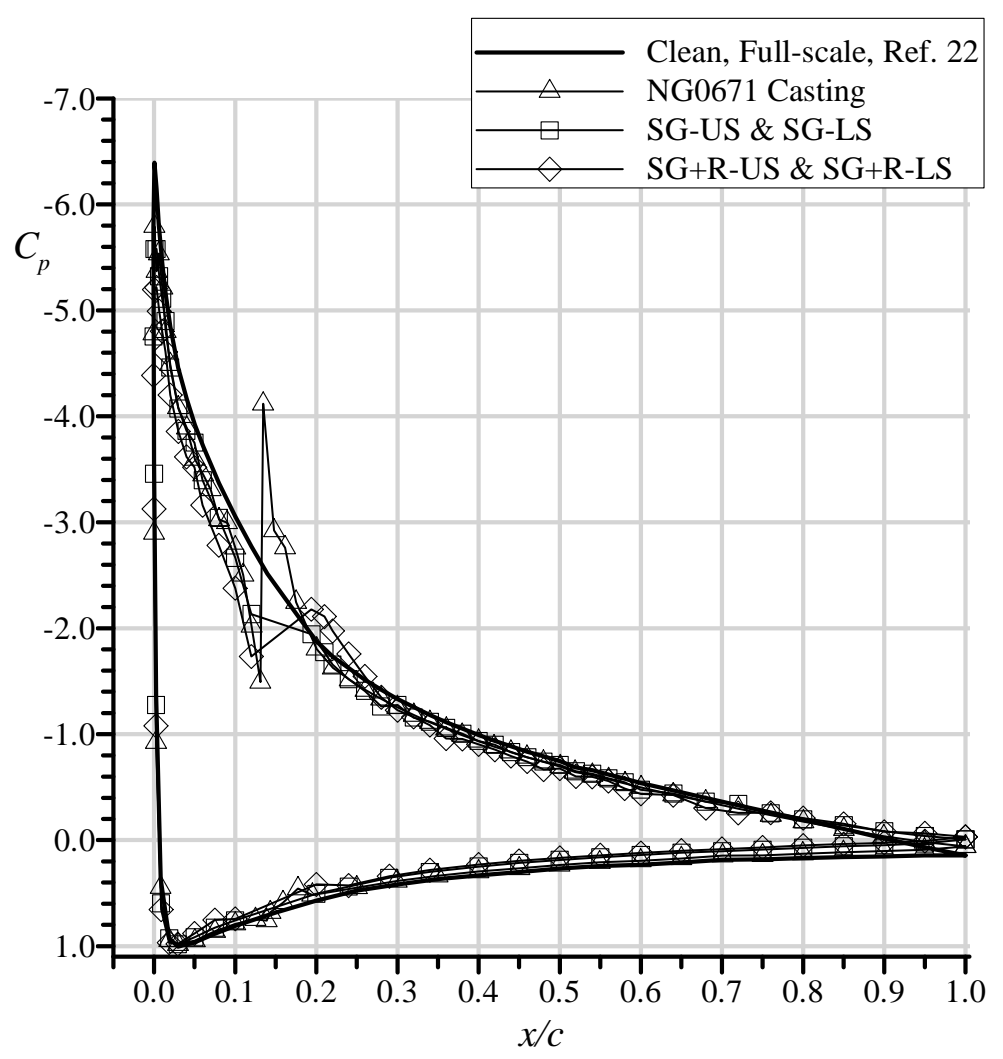

Figure 21. Comparison of Surface Pressure Distribution for Selected Subscale Runback-Ridge Simulations (at $R e=1.8 \times 10^{6}, M=0.18$ ) and the Full-Scale NG0671 Casting and Clean Configurations (at $R e=16.0 \times 10^{6}, M=0.20$ ), all at $\alpha=12.4^{\circ}$

Drag coefficient comparisons are more difficult to evaluate since there is usually not a single value of importance, as there is with maximum lift coefficient. A useful metric for comparing $C_{d}$ 
at multiple angles of attack is the percent root mean square (rms) difference in $C_{d}$ over an appropriate angle of attack range [12]. $C_{l}$ varied linearly with $\alpha$ over the angle-of-attack range used in this study. The value $\Delta C_{d, r m s}$ is a percentage and is computed by determining the rms of the percent difference in $C_{d}$ between the full-scale casting and subscale simulation at each angle of attack in the linear lift-coefficient range (a total of $N$ angles of attack):

$$
\Delta C_{d, r m s}=\sqrt{\frac{\sum_{i=1}^{N}\left(\frac{C_{d, \text { sim }}^{i}-C_{d, \text { casting }}^{i}}{C_{d, \text { casting }}^{i}} \times 100 \%\right)^{2}}{N}}
$$

While this parameter is useful for making comparisons over an angle of attack range, a disadvantage is that it does not give any indication as to whether the $C_{d}$ of a given subscale simulation is higher or lower than that of the full-scale casting. For this study, the selected angle of attack range was $-4^{\circ}$ to $12^{\circ}$. Figure 20 indicates that the SG-US \& SG-LS subscale simulation had the best overall comparison in $C_{d}$ to the airfoil with the NG0671 casting. The $\Delta C_{d, r m s}$ for this case was $13.0 \%$. The other two subscale simulations had $\Delta C_{d, r m s}$ values that were nearly twice as large. For comparison, the $\Delta C_{d, r m s}$ for the full-scale NG0671 casting relative to the clean airfoil was $162 \%$, indicating the large overall increase in drag due to the ice shape.

Since the addition of roughness to the upper-surface simple-geometry ridge resulted in a large deviation in $C_{d}$ relative to the NG0671 casting configuration, data were acquired with roughnesses added to the lower-surface ridge only. These data, labeled SG-US \& SG+R-LS, are shown in figure 22. As expected, the stalling characteristics were similar to the configuration with only the upper-surface simple-geometry ridge (figure 20), while the agreement in drag coefficient was also improved. The $\Delta C_{d, r m s}$ value was reduced to $10.2 \%$ for this configuration. Attempts at further improving the aerodynamic simulation were not successful. A threedimensional, lower-surface simulation was fabricated that closely modeled the individual ice elements of the NG0671 shape. This was tested along with the simple-geometry ridge on the upper surface (SG-US \& 3D-LS in figure 22). As expected, the influence of this change was primarily observed in the drag coefficient for $\alpha<4^{\circ}$. The corresponding values of $C_{d}$ were significantly higher than for the airfoil with the NG0671 casting. This led to a $\Delta C_{d, r m s}$ value of $14.3 \%$. Finally, simulated frozen rivulets were applied to the upper-surface simple-geometry ridge and to the lower-surface three-dimensional simulation (SG+Riv-US \& 3D+Riv-LS in figure 22). This simulation was tested because it represents perhaps the highest-fidelity subscale simulation possible using commercial off-the-shelf materials. Such a simulation may be considered "the most representative" without a priori knowledge of the full-scale, iced-airfoil aerodynamics. As shown in figure 22, the effect on performance was very similar to the addition of roughness to the simple-geometry ridges. The simulated frozen rivulets on the upper surface caused a reduction in maximum lift coefficient and stalling angle. The drag at angles of attack larger than $2^{\circ}$ was significantly increased. These results are consistent with Whalen, et al. [9], who noted that three-dimensional runback ridge simulations tended to yield larger performance penalties than their two-dimensional counterparts. 


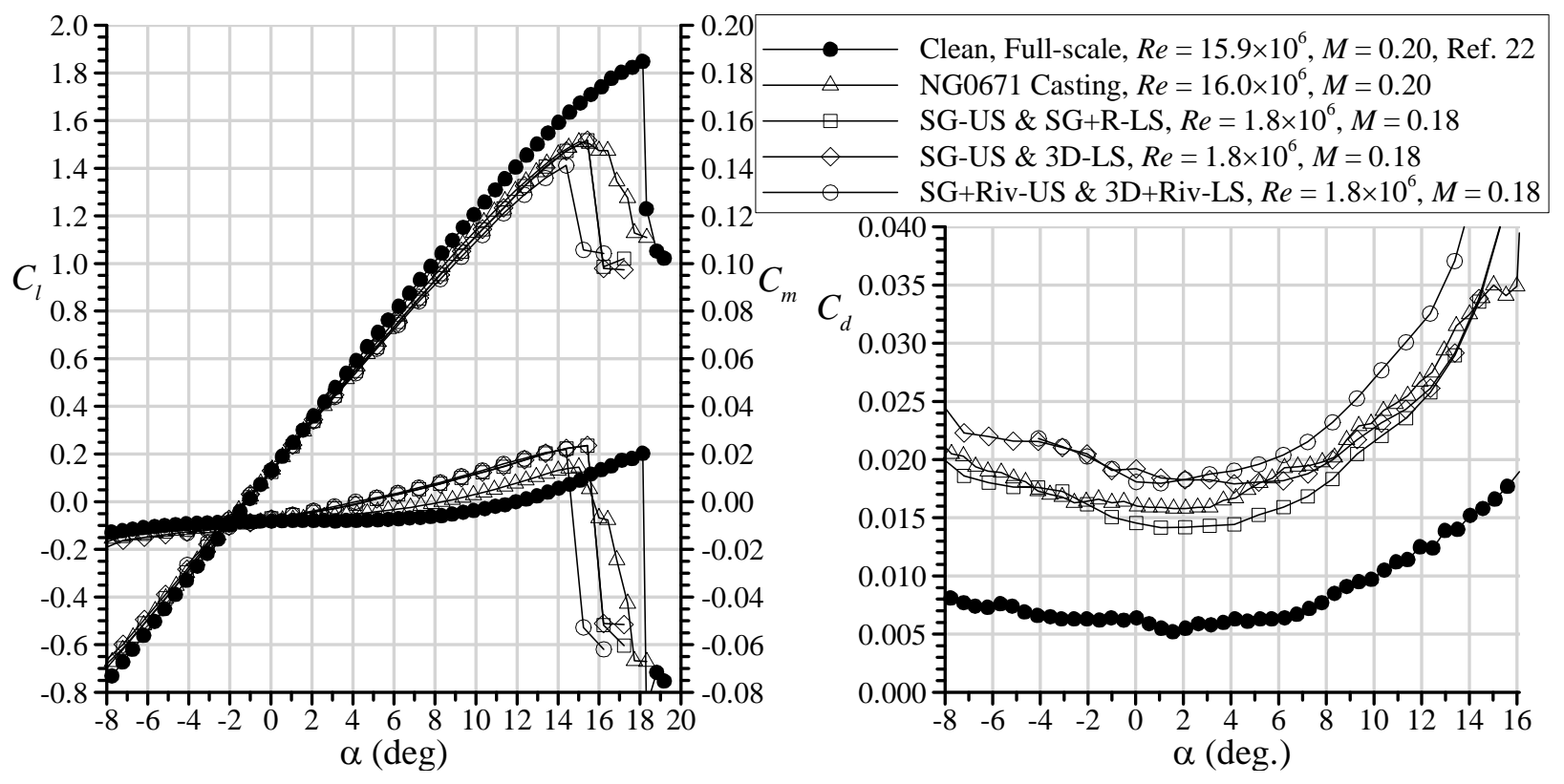

Figure 22. Comparison of $C_{l}, C_{m}$, and $C_{d}$ vs $\alpha$ for Various Subscale Runback-Ridge Simulations and the Full-Scale NG0671 Casting and Clean Configurations

The subscale simulation effectiveness is summarized for each configuration in table 5 where $\mathrm{C}_{l, \max }, \alpha_{\text {stall }}$, and $\Delta C_{d, r m s}$ were computed relative to the full-scale NG0671 casting configuration. According to these parameters, the best simulation was the simple-geometry ridge on the upper and lower surface with roughness applied to the lower-surface ridge only. This adequately simulated the full-scale iced-airfoil aerodynamics, with the exception of the stall type. This simulation on the subscale model stalled from the leading edge, in contrast to the full-scale iced airfoil that had a more gradual trailing-edge stall. However, none of the subscale simulations tested were able to reproduce the stall characteristics of the full-scale iced airfoil. In addition, the pitching-moment coefficient also exhibited greater angle of attack dependence for all of the subscale simulation configurations relative to the full-scale iced airfoil. As previously discussed, the addition of roughness to the upper-surface simple-geometry ridge resulted in larger performance degradations. Similar results, though less severe, were obtained when simulated frozen rivulets were applied to the upper-surface simple-geometry ridge. Variations in the lower-surface ridge simulations primarily affected drag coefficient, predominately at lower angles of attack. 
Table 5. Summary of Subscale Model Simulation Effectiveness for the NG0671 Ice Casting

\begin{tabular}{|l|c|c|c|}
\hline \multicolumn{1}{|c|}{ Simulation } & $\begin{array}{c}\text { Simulation } \\
\mathrm{Cl}_{\mathrm{l} \text { max }}-\text { Casting } \\
\mathrm{Cl}_{\mathrm{l} \text { max }}\end{array}$ & $\begin{array}{c}\text { Simulation } \\
\alpha_{\text {stall }}-\text { Casting } \alpha_{\text {stall }} \\
\text { (degrees) }\end{array}$ & $\begin{array}{c}\text { Simulation vs } \\
\text { Casting } \Delta C_{d, \text { rms }} \\
(\%)\end{array}$ \\
\hline SG-US & -0.01 & 0.4 & 25.6 \\
\hline SG-US \& SG-LS & 0.00 & 0.4 & 13.0 \\
\hline SG+R-US \& SG+R-LS & -0.22 & -1.6 & 23.8 \\
\hline SG-US \& SG+R-LS & 0.01 & 0.4 & 10.2 \\
\hline SG-US \& 3D-LS & 0.01 & 0.4 & 14.3 \\
\hline SG+Riv-US \& SG+Riv-LS & -0.10 & -0.6 & 16.7 \\
\hline
\end{tabular}

These data support the findings of previous researchers in regard to the aerodynamic effects of short, spanwise ridge ice shapes. At the subscale model Reynolds number, the simulated runback ice yielded slight increases in maximum lift coefficient and stalling angle compared to the clean configuration. The full-scale data from this study have shown that this apparent anomaly is due to the reduction in clean airfoil lift performance with Reynolds number. It is important to note that an exact scale model of the NG0671 casting was not tested on the subscale model nor was an exact scale model of the simple-geometry ridges tested on the full-scale model. This represents a Reynolds number gap between $R e=1.8 \times 10^{6}$ and $4.7 \times 10^{6}$ and a knowledge gap in the understanding of runback-ridge aerodynamics. The current research corroborates previous findings that the geometric details of the subscale simulation can have a significant effect on the iced-airfoil aerodynamics. Design and fabrication of three-dimensional subscale simulations or adding roughness are consistent with common practices. The present results indicate that such simulations tested at low Reynolds number will likely result in conservative performance degradations. This, too, is not well understood and may indicate that there are significant Reynolds number effects between $R e=1.8 \times 10^{6}$ and $4.7 \times 10^{6}$. At this time, it is not clear why a simple, two-dimensional, geometrically scaled ridge simulation is required to best represent the full-scale, high Reynolds number, iced-airfoil aerodynamics.

The boundary-layer based scaling methods investigated by Whalen, et al. [9, 10, 21, and 32] appear to produce subscale model performance that is unrealistically degraded from the full-scale case. In that research, the boundary-layer scaled ice shapes were nearly a factor of two larger than the geometrically scaled ice shapes. According to the present data, the larger boundarylayer-scaled simulations would result in unrealistically large performance penalties compared to the full-scale, high Reynolds number case. Simulation methods for Reynolds numbers lower than $1.8 \times 10^{6}$ may require alternatives to geometric scaling, as was the case for Lee, et al. [13]. Figure 23 shows the change in performance for the best simple-geometry simulation of the NG0671 casting with Reynolds and Mach number decreased to $1.0 \times 10^{6}$ and 0.10 , respectively. For the lower Reynolds number, the lift-curve slope approaching stall is reduced along with the maximum lift coefficient and stalling angle of attack. Interestingly, the pitching-moment and drag coefficients are largely unaffected by the decrease in Reynolds and Mach number. These data imply that an artificial ice shape smaller than the geometry-based scaling is required to adequately simulate the full-scale aerodynamics. The appropriate scaling length is unknown. 


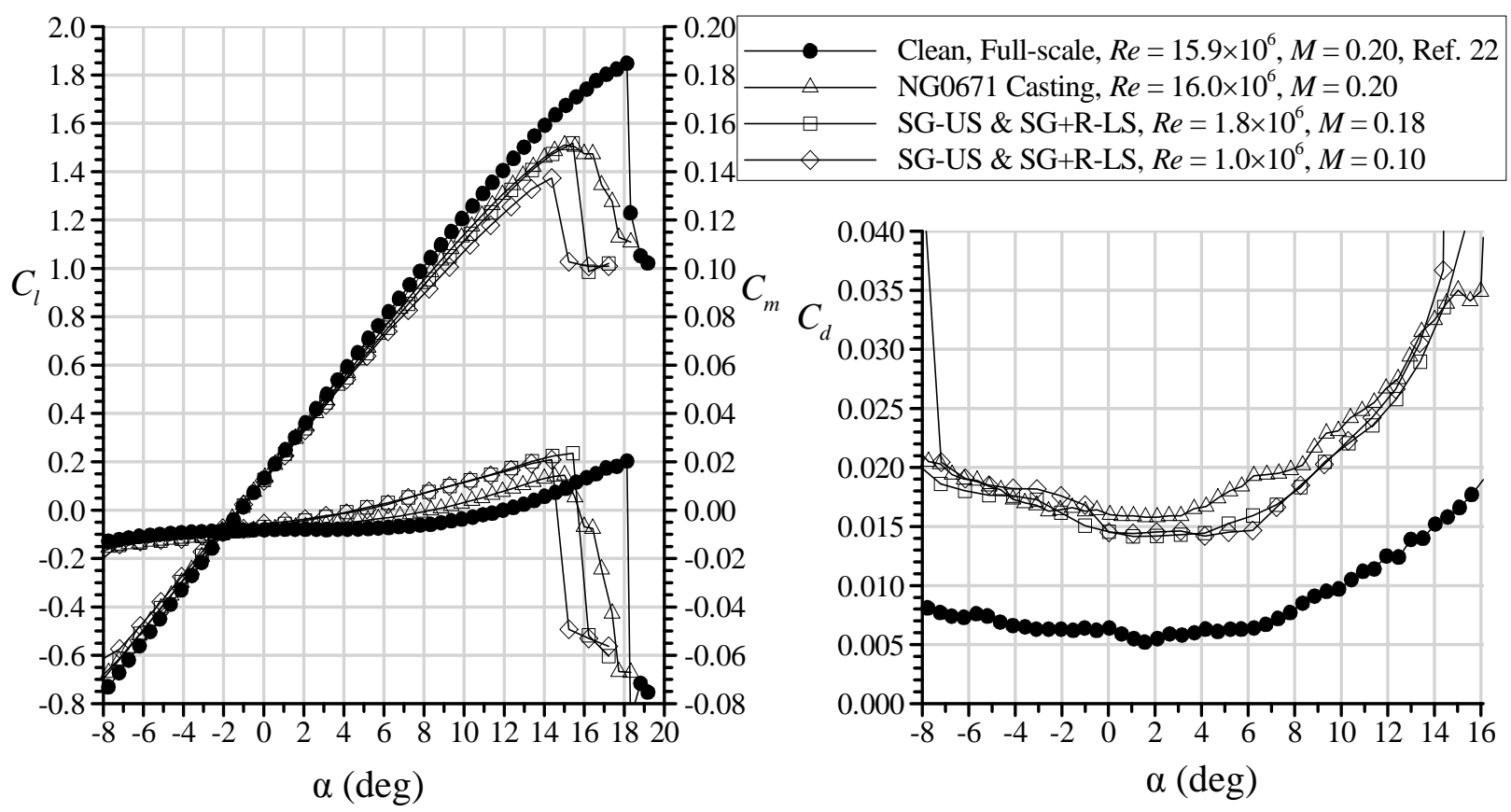

Figure 23. Effect of Reynolds and Mach Number on the Subscale Runback-Ridge Simulation Performance Effects

\subsection{AERODYNAMIC CLASSIFICATION OF SPANWISE RIDGE ICE.}

The data in figure 10 illustrate the contrasting aerodynamic effects between short spanwise ridges, as exemplified by the NG0671 shape, and tall spanwise ridges, as exemplified by the EG1159 shape. Clearly, the aerodynamics are fundamentally different. The ice accretion classification developed by Bragg, et al. [2] for spanwise ridges was primarily based upon research related to tall ridges similar to the EG1159 shape. In this report, a subclassification is proposed that divides spanwise ridge ice into short and tall ridges. The definitions of these terms are not to be taken in regard to the physical height, but rather the associated effect on the flow field and pressure distribution. Specifically, the distinction between short and tall ridges lies in consideration of the separation bubble generated by the presence of the spanwise ridge and the resulting aerodynamics.

The subclassification is analogous to the separation bubble nomenclature proposed by Tani [33] in 1964. In his review, Tani studied airfoil separation bubble characteristics. He defined the terms short and long, not based upon length, but upon the effect on pressure distribution. Tani wrote, "The presence of a long bubble makes the pressure distribution radically different from that in inviscid flow, with the result that the sharp suction peak near the leading edge is not realized. Instead, a suction plateau of a reduced level extends over the region occupied by the bubble length.” In contrast, a short bubble has a minimal effect on the pressure distribution and leading-edge suction peak. The distinction between short and tall spanwise ridge ice can be made in terms of the resulting separation bubble and its effect on the flow field as manifest in the pressure distribution. 
Numerous investigations into the aerodynamics of tall spanwise ridge ice shapes have been conducted [6-8 and 34-36] and the results are very briefly summarized here. As previously mentioned, the salient feature of tall spanwise ridge flow fields is the separation bubble that forms downstream of the ice shape. The resulting redistribution of surface pressure is significant for the EG1159 shape, as illustrated in figure 12. The iced-airfoil pressure distribution bears almost no similarity to the clean airfoil pressure distribution at the same angle of attack. Lee and Bragg [6] documented the growth of the upper-surface separation bubble with angle of attack for the tall, forward-facing, quarter-round, spanwise ridge shape using surface-oil flow visualization. The $k / c=0.0139$ ice shape was located at $x / c=0.10$ on the upper surface of the NACA $23012 \mathrm{~m}$ airfoil and tested at $R e=1.8 \times 10^{6}$ and $M=0.18$. The bubble reattachment region was centered at about $x / c=0.42$ at $\alpha=0^{\circ}$. The bubble grew rapidly with increasing angle of attack, until the reattachment region reached the trailing edge at about $\alpha=4^{\circ}$, precipitating the stall with maximum lift coefficient of about 0.25. As discussed at length by Bragg, et al. [2], these large separation bubbles are known to have large-scale unsteady characteristics. Since the surface-oil flow visualization technique is essentially a time-averaged method, only the region of mean reattachment was indicated. Also investigated were the effect of ridge height, cross-sectional geometry, location, and airfoil geometry. The height of the spanwise ridge was found to have a strong influence on the iced-airfoil aerodynamics as well as the chordwise location of the ridge for certain airfoils. Cross-sectional geometry was also found to be an important factor. As discussed in connection with figure 17, there were negligible Reynolds number effects on maximum lift coefficient at constant Mach number down to $R e=2.0 \times 10^{6}$. Lee and Bragg [6 and 7] showed continued Reynolds number independence down to $R e=1.0 \times 10^{6}$ and $M=0.10$ for the $k / c=0.0139$ quarter-round shape located at $x / c=0.10$. It is clear that tall spanwise ridge shapes have a large effect on the airfoil pressure distribution in terms of deviation from the clean configuration. This is manifested through a large separation bubble that grows in size (in the time-averaged sense) with small increases in angle of attack. Finally, the effect of Reynolds number on the flow field and performance has been shown to be negligible for the iced airfoil down to $R e=1.0 \times 10^{6}$.

Short spanwise ridges exemplified by the NG0671 shape have different characteristics. As discussed in connection with figure 12 (also shown in figure 13), the effect of the simulated runback ridge on the pressure distribution was only a localized disturbance in the immediate vicinity of the ridge (both upper and lower surfaces for the NG0671 configuration); elsewhere, the surface pressure closely matched that of the clean airfoil. Like Tani's short and long bubbles, this distinction-effect on pressure distribution-determines what is a short or tall spanwise ridge shape. The question then remains to determine how obvious this distinction may be for shapes of intermediate heights. Whalen [32] performed an extensive parametric study of twodimensional, square-cylinder, simple-geometry simulations of spanwise ridges on a NACA 3415 airfoil at $R e=1.8 \times 10^{6}$ and $M=0.18$. The effect on pressure distribution for increasing ice-shape height for two different angles of attack is shown in figure 24. This airfoil model was equipped with a plain flap with a hinge located at $x / c=0.75$. The flap was not deflected for these experiments and the lower-surface gap was sealed. The data for $\alpha=10^{\circ}$ show the increasing aerodynamic effect of the square-ridge shapes for increasing height. The large discontinuity in $C_{p}$ is observed at the ice-shape location of $x / c=0.16$ on the upper surface. Clearly, the pressure distribution for the smallest shape $(k / c=0.0035)$ had features analogous to the NG0671 runback ridge. In the former case, the presence of the simple-geometry ridge caused a slight decrease in 
the suction pressure from the leading-edge peak downstream to the ice shape (at $x / c=0.16$ ) relative to the clean configuration. Increasing the angle of attack to $13^{\circ}$ shows much better alignment with the clean surface pressures, except in the immediate vicinity of the ridge.
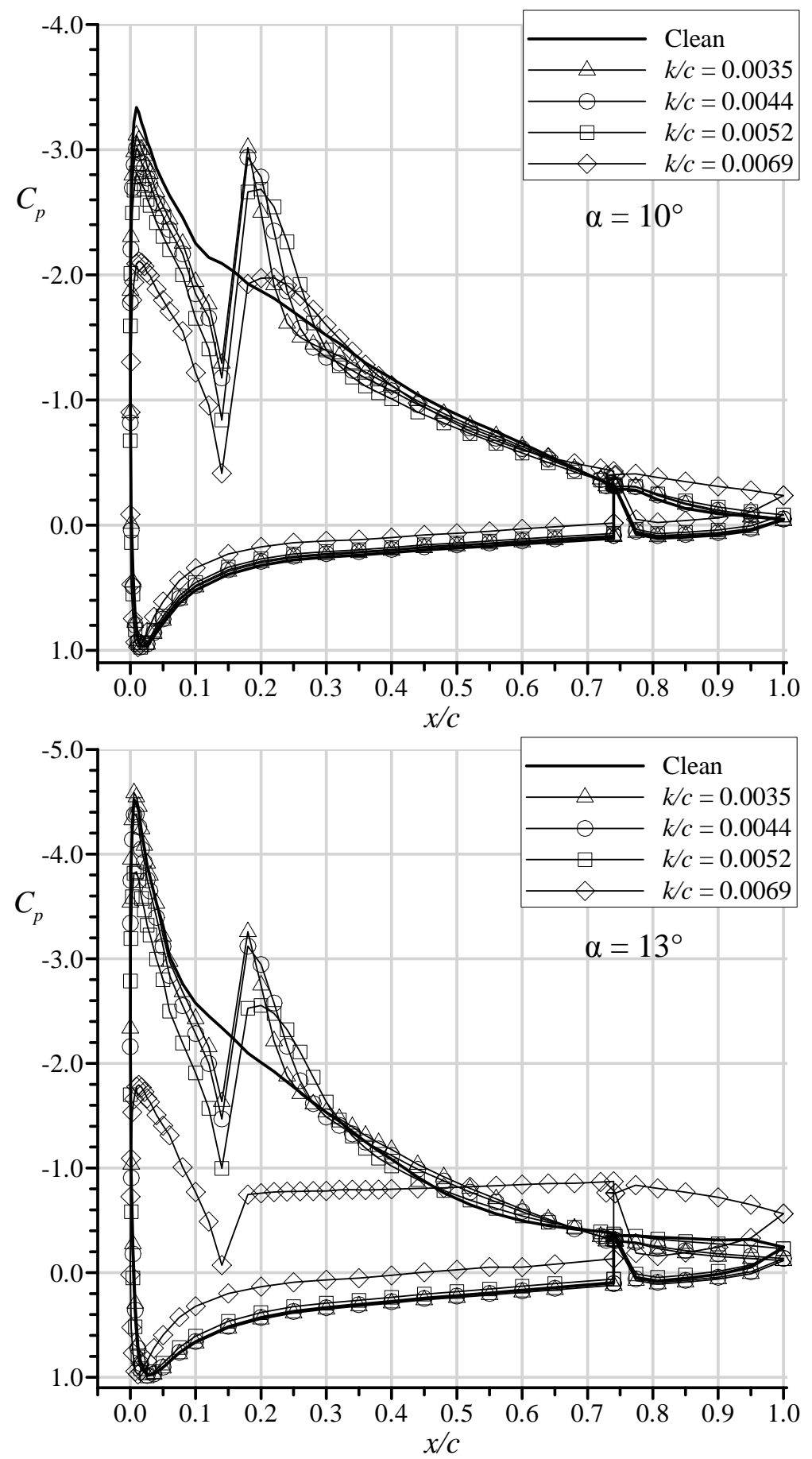

Figure 24. Surface Pressure Effect of Square-Cylinder Spanwise Ridge Height at $x / c=0.16$ on the Upper Surface of the NACA 3415 Airfoil at $R e=1.8 \times 10^{6}, M=0.18$ [32] 
This behavior is contrasted with the $k / c=0.0069$ square shape. Even at the lower angle of attack of $10^{\circ}$, the effect of this simulated ice shape on the surface pressure was profound. It exhibited the classic characteristics of tall spanwise ridges. The pressure distribution for the iced airfoil had significant deviation from the clean airfoil configuration. The pressure plateau from $x / c=$ 0.17 to 0.24 and the subsequent gradual pressure recovery are indicative of a large separation bubble. This was confirmed via surface-oil flow visualization that indicated a time-averaged reattachment location at $x / c=0.45$. The deviation of surface pressure from the clean configuration downstream of $x / c=0.65$ on the upper surface was indicative of boundary-layer separation that was also confirmed in the surface-oil flow visualization. The increase in angle of attack to $16^{\circ}$ for this configuration indicates a stalled flow condition. Based upon these observations, the distinction between the $k / c=0.0035$ and 0.0069 shapes is clear.

For the intermediate-height, simple-geometry ridges, the distinction between what would be considered tall or short may not be as obvious. However, further comparison of the pressure distributions in figure 24 reveals some important characteristics. For $\alpha=10^{\circ}$, there are only minor differences in the pressure distributions for the $k / c=0.0044$ and 0.0052 configurations. The biggest difference is that the airfoil with the $k / c=0.0044$ shape attained a lower pressure just downstream of the ridge $(x / c=0.018)$ (having nearly the same value as for the $k / c=0.0035$ shape $\left.\left(C_{p} \approx-2.9\right)\right)$. The $k / c=0.0044$ shape also resulted in a steeper pressure recovery while the $k / c=0.0052$ configuration exhibited a short pressure plateau region with more gradual pressure recovery. The latter is indicative of a large separation bubble. Therefore, based on the proposed definition, the $k / c=0.0044$ ridge would be considered a short spanwise ridge, while the $k / c=0.0052$ would be considered a tall spanwise ridge. This is confirmed in the pressure data for $\alpha=13^{\circ}$. Here, the pressure distribution for the $k / c=0.0044$ configuration conformed to the clean airfoil $C_{p}$, except in the immediate vicinity of the ridge, while the pressure distribution for the $k / c=0.0052$ configuration more clearly indicates the presence of a large separation bubble. Therefore, for the case of a spanwise ridge ice shape located at $x / c=0.16$ on the upper surface of the NACA 3415 airfoil at $R e=1.8 \times 10^{6}$ and $M=0.18$, the boundary between what is a short spanwise ridge and tall spanwise ridge lies somewhere between $k / c=0.0044$ and 0.0056 . Of course, this distinction is somewhat arbitrary. In reality, there is clearly an overlap region in the proposed subclassification as there is in any continuum.

Whalen, et al. [9, 10, 21, and 32] further investigated the flow fields for the $k / c=0.0035$ and 0.0069 spanwise ridges using surface-oil flow visualizations and hot-wire, boundary-layer measurements. Consistent with previous findings for tall spanwise ridges was the presence of a large separation bubble that grew rapidly with angle of attack for the $k / c=0.0069$ ridge. The flow field for the airfoil with the $k / c=0.0035$ spanwise ridge was fundamentally different. Although there was a small separation bubble, the reattachment location was nearly constant over a large angle of attack range. Figure 25 is a plot of the bubble reattachment location versus angle of attack for three different configurations. Included with the square-cylinder shapes on the NACA 3415 airfoil are data from Lee and Bragg [6] for the $k / c=0.0139$ quarter-round shape on the NACA $23012 \mathrm{~m}$ airfoil. The data clearly illustrate the difference in angle of attack dependence of the separation bubble reattachment location. The error bars illustrate the size of the reattachment region due to the aforementioned unsteady characteristics associated with these large separation bubbles. In contrast to the tall shapes, the error bars for the short, $k / c=0.0035$ shape on the NACA 3415 airfoil illustrate the more steady character of the bubble. For the tall 
ridge configurations, the stall was driven by the increasing size of the separation bubble (thin airfoil stall). But in the case of the short ridge configuration, the principle stall mechanism was from trailing-edge separation moving forward with increasing angle of attack (trailing-edge stall).

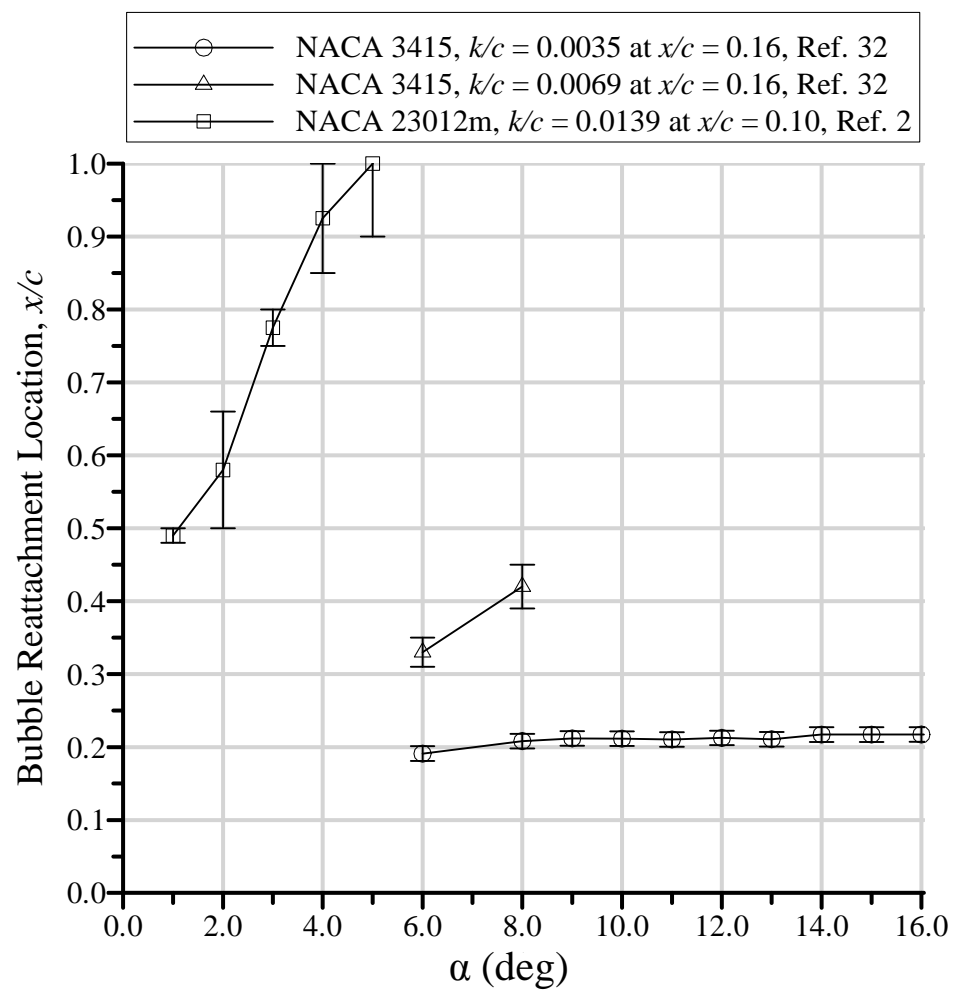

Figure 25. Comparison of Separation Bubble Reattachment Location Based on Surface-Oil Flow Visualization Results for Tall and Short Spanwise Ridges, all Data at $R e=1.8 \times 10^{6}, M=0.18$

The differences in the separation bubble details are also illustrated in the single-component, hotwire mean and rms velocity profiles in figures 26 and 27 . The profiles were measured on the NACA 3415 airfoil upper surface for the $k / c=0.0035$ and 0.0069 ridge shapes at $\alpha=8^{\circ}$, corresponding to the surface-oil flow visualization data in figure 25 . Since a single-component hot wire is not capable of indicating flow direction, the data close to the wall $(n / k=0$ in figures 24 and 25) must be carefully interpreted. First, for the $k / c=0.0035$ case (figure 26), the mean and rms velocity profiles at $x / c=0.163$ were measured immediately downstream of the ridge. The remaining profiles, at progressive downstream locations are consistent with an attached, developing turbulent boundary layer. For the larger ridge, the rms velocity profiles indicate a significant departure from the airfoil surface of the shear layer downstream of the ridge. The magnitude of the peak rms velocities are much larger for the larger ridge, further indicating the fundamentally unsteady nature of the separation region formed downstream of this shape. This is very different from the smaller ridge case where the shear layer remains close to the surface as indicated by the rms velocity profiles. Several of the mean velocity profiles downstream of the larger ridge have an inflection point consistent with separated flow in this region. These measurements, together with the surface pressure and surface-oil flow visualization data, indicate a large separation zone for the tall ridge and minimal flow disturbance for the short ridge. 

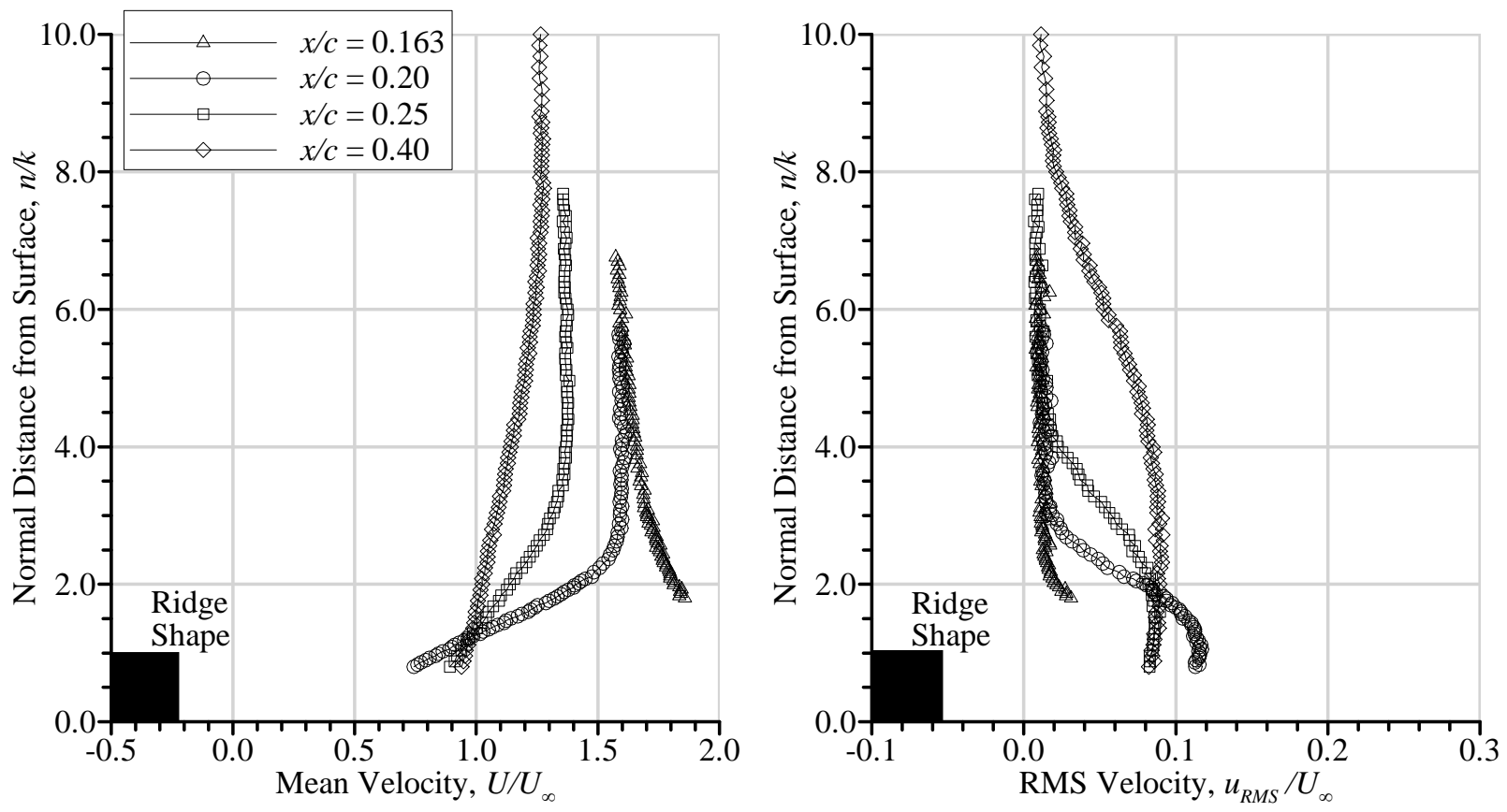

Figure 26. Mean and rms Velocity Profiles Downstream of $k / c=0.0035$ Square-Cylinder Ridge Shape Located at $x / c=0.16$ on the NACA 3415 Airfoil With $\alpha=8^{\circ}, R e=1.8 \times 10^{6}$, and $M=0.18$ [32]
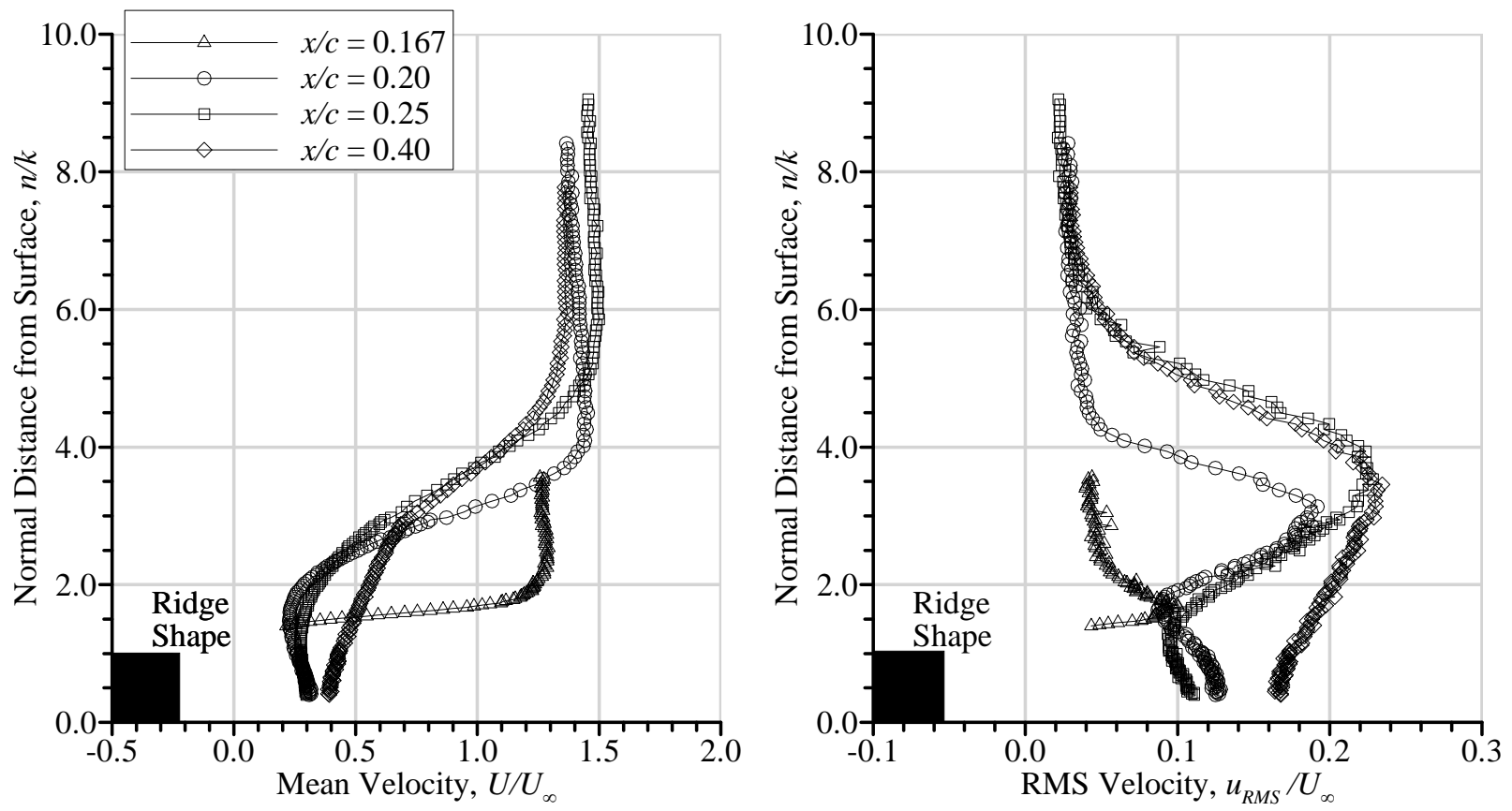

Figure 27. Mean and rms Velocity Profiles Downstream of $k / c=0.0069$ Square-Cylinder Ridge Shape Located at $x / c=0.16$ on the NACA 3415 Airfoil With $\alpha=8^{\circ}, R e=1.8 \times 10^{6}$, and $M=0.18$ [32] 
The chordwise location of upper-surface spanwise ridges is known to have a significant effect on the aerodynamics. With respect to the present discussion, the chordwise location can influence what is classified as a short or tall spanwise ridge. Whalen [32] studied this effect for the $k / c=0.0035$ square-cylinder shape on the NACA 3415 airfoil. The effect on pressure distribution is shown in figure 28 for two locations. The baseline location was $x / c=0.16$, where the shape is clearly classified as "short." Locating the same artificial ice shape at $x / c=0.06 \mathrm{had}$ the effect of significantly altering the pressure distribution. Thus, the same geometry had characteristics of a tall spanwise ridge when located farther forward on the airfoil. The corresponding lift data indicated a significant reduction in maximum lift coefficient and stalling angle of attack relative to the clean configuration at the same Reynolds and Mach number. This stands in contrast to the lift enhancement due to the same artificial ice shape located at the downstream location, $x / c=0.16$. This effect of chordwise location is consistent with the short spanwise ridge studies of Calay, et al. [4] and Papadakis, et al. [5], where lift enhancements were observed for downstream locations while the upstream locations resulted in significant degradations. The effect of chordwise location is driven by a number of factors, such as boundary-layer thickness. The airfoil boundary layer is generally thinner near the leading edge (depending on the transition location), so that even relatively short ridges are many times larger than the local boundary-layer thickness. This and other factors can result in a larger separation bubble downstream of the ridge, which in turn results in a larger effect on the surface pressure distribution and larger performance degradations.

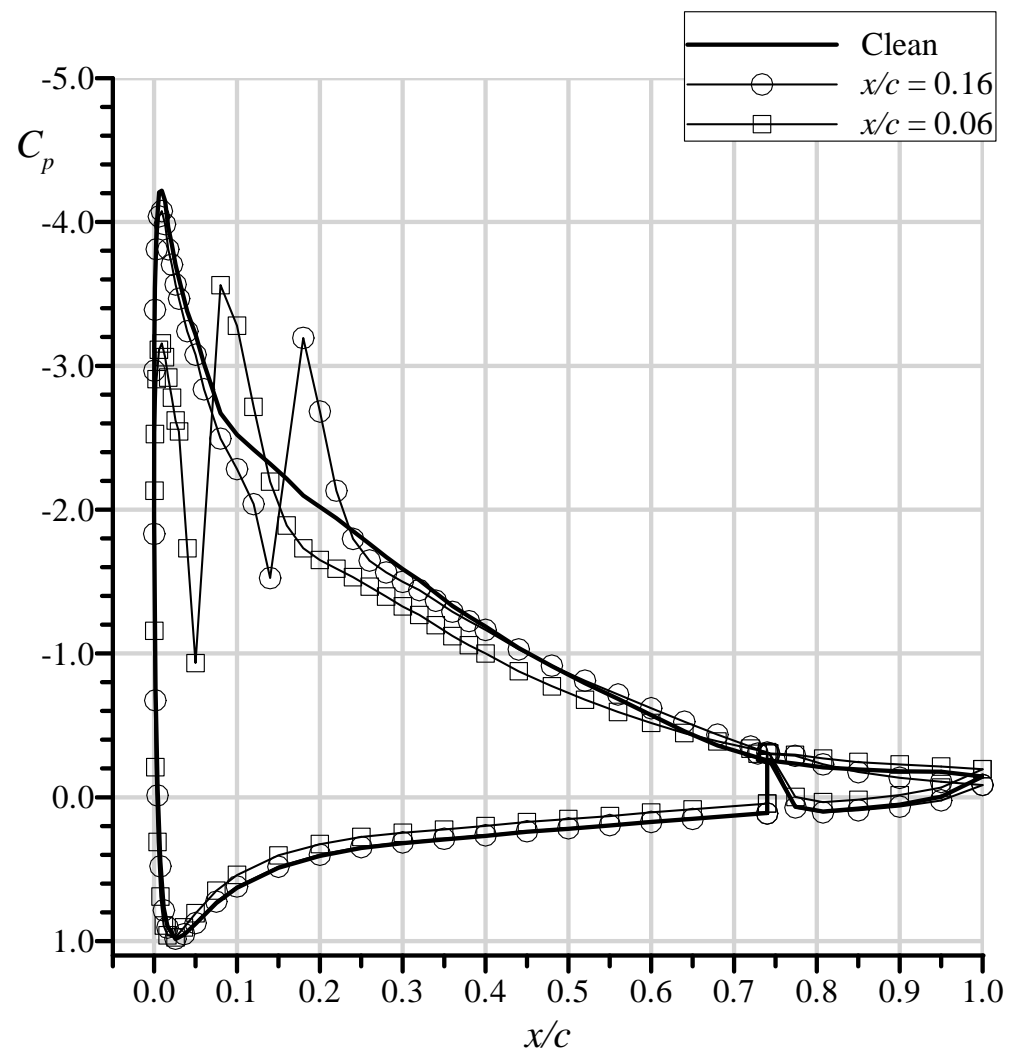

Figure 28. Surface Pressure Effect of $k / c=0.0035$ Square-Cylinder Spanwise Ridge Chordwise Location on the Upper Surface of the NACA 3415 Airfoil at $\alpha=12^{\circ}, R e=1.8 \times 10^{6}$, and $M=0.18$ [32] 


\section{CONCLUSIONS.}

This report presents the results of recent investigations into the aerodynamics of simulated runback ice accretion on airfoils. Aerodynamic testing was performed on a full-scale model using a high-fidelity, ice-casting simulation at near-flight Reynolds numbers $(R e)$. In addition, follow-on subscale tests were conducted with low-fidelity simulations on a quarter-scale model at low Reynolds numbers. The high-fidelity, ice-casting simulation was fabricated from an ice accretion mold acquired during an icing tunnel test on a full-scale model with an anti-icing system. It was attached to the leading edge of a 72-inch (1828.8-mm) chord National Advisory Committee for Aeronautics (NACA) 23012 airfoil model. Aerodynamic performance tests were conducted at the Office National d'Etudes et de Recherches Aérospatiales (French Aeronautics and Space Research Center) (ONERA) F1 pressurized wind tunnel over a Re range of $4.7 \times 10^{6}$ to $16.0 \times 10^{6}$ and a Mach number $(M)$ range of 0.10 to 0.28 . For $R e=16.0 \times 10^{6}$ and $M=0.20$, the simulated runback ice accretion on the airfoil decreased the maximum lift coefficient from 1.82 to 1.51 and decreased the stalling angle of attack from $18.1^{\circ}$ to $15.0^{\circ}$. The pitching-moment slope was also increased and the drag coefficient was increased by more than a factor of two. In general, the performance effects were insensitive to Reynolds and Mach number changes over the range tested. While these aerodynamic penalties are significant, they are generally less than the penalties associated with full-scale, high-fidelity, leading-edge ice simulations, including roughness, on the NACA 23012 airfoil.

The results from the full-scale tests were used to evaluate simulation methods for runback ice accretion. Aerodynamic tests were conducted on a quarter-scale NACA 23012 model (18-inch (457.2-mm) chord) at $R e=1.8 \times 10^{6}$ and $M=0.18$, using low-fidelity, geometrically scaled simulations of the full-scale casting. It was found that simple, two-dimensional simulations of the upper- and lower-surface runback ridges provided the best representation of the full-scale, high Reynolds number aerodynamics with the ice-casting simulation. This adequately simulated the full-scale, iced-airfoil aerodynamics, with the exception of the stall characteristics. The simple, two-dimensional simulation on the subscale model resulted in stalling from the leading edge, in contrast to the full-scale iced airfoil that had a more gradual trailing-edge stall. However, none of the subscale simulations tested were able to reproduce the stall characteristics of the full-scale iced airfoil. The pitching-moment coefficient also exhibited greater angle of attack dependence for all of the subscale simulation configurations relative to the full-scale iced airfoil. Addition of grit roughness to the lower-surface simple-geometry ridge further improved the simulation accuracy in the drag coefficient. However, the addition of roughness to the uppersurface simple-geometry ridge resulted in larger performance degradations (in lift and drag) compared to the full-scale, high Reynolds number configuration. A higher-fidelity simulation of the runback ice accretion that included geometrically scaled, three-dimensional features also resulted in larger performance degradations than what was measured on the full-scale model.

At this time, it is not clear why a simple, two-dimensional, geometrically scaled ridge simulation is required to best represent the full-scale, high Reynolds number iced-airfoil aerodynamics. The fact that the aerodynamic performance of the subscale simulations is very sensitive to the geometric details, such as the addition of surface roughness, implies that Reynolds number effects may not be negligible for this type of ice accretion. An exact scale model of the NG0671 casting was not tested on the subscale model nor was an exact scale model of the simple- 
geometry ridges tested on the full-scale model. This represents a Reynolds number gap between $R e=1.8 \times 10^{6}$ and $4.7 \times 10^{6}$, and a knowledge gap in the understanding of runback-ridge aerodynamics. Therefore, more research specifically targeting this Reynolds number range is recommended.

From both past and current research, the appropriate scaling length for the runback ice accretion is unclear. The previously proposed boundary-layer thickness length scale would result in subscale simulations that were too large and would thus result in larger performance degradations compared to the full-scale, high Reynolds number configuration. Ideally, a length scale could be determined that was not explicitly dependent upon height and location of the ice accretion. Such a length scale may be dependent on Reynolds number. More research is required to determine the appropriate length scale for subscale ridge simulations, particularly for Reynolds numbers less than $1.8 \times 10^{6}$.

The results of this investigation were used develop a new subclassification of spanwise ridge ice that distinguishes between short and tall ridges. This subclassification is based upon the flow field and resulting aerodynamic characteristics, regardless of the physical size of the ridge and the ice accretion mechanism. Tall spanwise ridges have a profound effect on the airfoil flow field with a large (and often unsteady) separation bubble that grows rapidly with angle of attack, precipitating the stall at low-lift coefficient and angle of attack. Previous research has shown that the aerodynamic effect of tall spanwise ridge ice is insensitive to Reynolds number over a large range from $R e>1.0 \times 10^{6}$. In contrast, short spanwise ridges are characterized by a small, stable separation bubble formed in the immediate vicinity of the ridge. This small separation zone results in a limited effect on the airfoil pressure distribution relative to the clean configuration. Significant differences in surface pressure are only observed at the ridge location. The separation bubble does not significantly increase in size with angle of attack. Thus, the stall of the iced airfoil is generally governed by trailing-edge separation moving forward with increasing angle of attack (trailing-edge stall). In some cases, the airfoil may stall from the leading edge or from the ridge itself. More research is needed to determine the appropriate simulation methods for short ridges, particularly for Reynolds numbers less than $1.8 \times 10^{6}$.

\section{REFERENCES.}

1. Bragg, M.B., Broeren, A.P., Addy, H.E., Jr., Potapczuk, M., Guffond, D., and Montreuil, E., “Airfoil Ice-Accretion Aerodynamics Simulation,” AIAA Paper 2007-0085, January 2007.

2. Bragg, M.B., Broeren, A.P., and Blumenthal, L.A., "Iced-Airfoil Aerodynamics," Progress in Aerospace Sciences, Vol. 41, No. 5, July 2005, pp. 323-418.

3. Gray, V.H. and von Glahn, U.H., "Effect of Ice and Frost Formations on Drag of the NACA 651-212 Airfoil for Various Models of Thermal Ice Protection,” NACA TN-2962, June 1953.

4. Calay, R.K., Holdo, A.E., Mayman, P., and Lun, I., "Experimental Simulation of Runback Ice,” Journal of Aircraft, Vol. 34, No. 2, March-April 1997, pp. 206-212. 
5. Papadakis, M. and Gile-Laflin, B.E., "Aerodynamic Performance of a Tail Section With Simulated Ice Shapes and Roughness,” AIAA Paper 2001-0539, January 2001.

6. Lee, S. and Bragg, M.B., "Experimental Investigation of Simulated Large-Droplet Ice Shapes on Airfoil Aerodynamics," Journal of Aircraft, Vol. 36, No. 5, SeptemberOctober 1999, pp. 844-850.

7. Lee, S. and Bragg, M.B., "Investigation of Factors Affecting Iced-Airfoil Aerodynamics,” Journal of Aircraft, Vol. 40, No. 3, May-June 2003, pp. 499-508.

8. $\quad$ Broeren, A.P., Lee, S., LaMarre, C.M., and Bragg, M.B., "Effect of Airfoil Geometry on Performance With Simulated Ice Accretions, Vol. 1: Experimental Investigation,” FAA report DOT/FAA/AR-03/64, August 2003.

9. Whalen, E.A., Broeren, A.P., and Bragg, M.B., "Aerodynamics of Scaled Runback Ice Accretions,” Journal of Aircraft, Vol. 45, No. 2, March-April 2008, pp. 591-603.

10. Whalen, E.A., Broeren, A.P., and Bragg, M.B., "Considerations for Aerodynamic Testing of Scaled Runback Ice Accretions,” AIAA Paper 2006-0260, January 2006.

11. Broeren, A.P. and Bragg, M.B., "Effect of Airfoil Geometry on Performance With Simulated Intercycle Ice Accretions,” Journal of Aircraft, Vol. 42, No. 1, JanuaryFebruary 2005, pp. 121-130.

12. Busch, G.T., Broeren, A.P., and Bragg, M.B., “Aerodynamic Fidelity of Subscale, TwoDimensional Ice Accretion Simulations,” AIAA Paper 2008-7062, August 2008.

13. Lee, S., Ratvasky, T.P., Thacker, M., and Barnhart, B.P., "Geometry and ReynoldsNumber Scaling on an Iced Business-Jet Wing,” AIAA Paper 2005-1066, January 2005.

14. Desplas, P., "F1 Pressurized Subsonic Wind Tunnel User's Guide,” Large Technical Facilities, Le-Fauga-Mauzac Wind Tunnels Department, ONERA, France, November 1998.

15. Allen, H.J. and Vincenti, W.G., "Wall Interference in a Two-Dimensional-Flow Wind Tunnel, With Consideration of the Effect of Compressibility,” NACA Report 782, 1944.

16. Kline, S. and McClintock, F.A., "Describing Uncertainties in Single Sample Experiments," Mechanical Engineering, Vol. 75, No. 1, 1953, pp. 3-8.

17. Coleman, H.W. and Steele, W.G., Experimentation and Uncertainty Analysis for Engineers, Wiley-Interscience, New York, 1989.

18. Busch, G.T., "Ice Accretion Aerodynamic Simulation on a Subscale Model," M.S. Thesis, Department of Aerospace Engineering, University of Illinois, Urbana, Illinois, 2006. 
19. Blumenthal, L.A., "Surface Pressure Measurement on a Three-Dimensional Ice Shape," M.S. Thesis, Department of Aerospace Engineering, University of Illinois, Urbana, Illinois, 2005.

20. Whalen, E.A., Broeren, A.P., Bragg, M.B., and Lee, S., "Characteristics of Runback Ice Accretions on Airfoils and Their Aerodynamic Effects,” AIAA Paper 2005-1065, January 2005.

21. Whalen, E.A., Broeren, A.P., and Bragg, M.B., "Characteristics of Runback Ice Accretions and Their Aerodynamic Effects,” FAA report DOT/FAA/AR-07/16, April 2007.

22. Broeren, A.P., Bragg, M.B., Addy, H.E., Jr., Lee, S., Moens, F., and Guffond, D., "Effect of High-Fidelity Ice Accretion Simulations on the Performance of a Full-Scale Airfoil Model,” AIAA Paper 2008-0434, January 2008.

23. Busch, G.T., Broeren, A.P., and Bragg, M.B., "Aerodynamic Simulations of a Horn-Ice Accretion on a Subscale Model," Journal of Aircraft, Vol. 45, No. 2, March-April 2008, pp. 604-613.

24. Broeren, A.P., Busch, G.T., and Bragg, M.B., "Aerodynamic Fidelity of Ice Accretion Simulation on a Subscale Model," SAE Paper 2007-01-3285, September 2007, also published in SAE 2007 Transactions Journal of Aerospace, Vol. 116, Sec. 1, August 2008, pp. 560-575.

25. McCullough, G.B. and Gault, D.E., "Examples of Three Representative Types of AirfoilSection Stall at Low-Speed,” NACA TN-2502, September 1951.

26. Broeren, A.P., Bragg, M.B., and Addy, H.E., Jr., "Effect of Intercycle Ice Accretions on Aerodynamic Performance,” Journal of Aircraft, Vol. 41, No. 1, January-February 2004, pp. 165-174.

27. Addy, H.E., Jr., Broeren, A.P., Zoeckler, J.G., and Lee, S., “A Wind Tunnel Study of Icing Effects on a Business Jet Airfoil,” AIAA Paper 2003-0727, January 2003, also published as NASA TM-2003-212124, February 2003.

28. Addy, H.E., Jr., "Ice Accretions and Icing Effects for Modern Airfoils,” NASA/TP-2000210031, also published as FAA report DOT/FAA/AR-99/89, April 2000.

29. Addy, H.E., Jr. and Chung, J.J., "A Wind Tunnel Study of Icing Effects on a Natural Laminar Flow Airfoil,” AIAA Paper 2000-0095, January 2000, also published as NASA TM-2000-209775, January 2000.

30. Broeren, A.P., Bragg, M.B., and Addy, H.E., Jr., "Flowfield Measurements About an Airfoil With Leading-Edge Ice Shapes," Journal of Aircraft, Vol. 43, No. 4, July-August, 2006, pp. 1226-1234. 
31. Kim, H.S., "Effect of Leading-Edge Ice Accretion Geometry on Airfoil Performance," M.S. Thesis, Department of Aeronautical and Astronautical Engineering, University of Illinois, Urbana, Illinois, 2004.

32. Whalen, E.A., “Aerodynamics of Runback Ice Accretions,” Ph.D. Dissertation, Department of Aerospace Engineering, University of Illinois, Urbana, Illinois, 2007.

33. Tani, I., “Low-Speed Flows Involving Separation Bubbles,” Progress in Aeronautical Sciences, Vol. 5, No. 2, 1964, pp. 70-103.

34. Lee, S., Dunn, T., Gurbacki, H., Bragg, M., and Loth, E., "An Experimental and Computational Investigation of Spanwise-Step Ice Shapes on Airfoil Aerodynamics," AIAA Paper 98-0490, January 1998.

35. Bragg, M. and Loth, E., "Effects of Large-Droplet Ice Accretion on Airfoil and Wing Aerodynamics and Control,” FAA report DOT/FAA/AR-00/14, April 2000.

36. Lee, S., “Effects of Supercooled Large-Droplet Icing on Airfoil Aerodynamics,” Ph.D. Dissertation, Department of Aeronautical and Astronautical Engineering, University of Illinois, Urbana, Illinois, 2001. 


\begin{tabular}{|c|c|c|c|c|c|}
\hline \multicolumn{5}{|c|}{ REPORT DOCUMENTATION PAGE } & $\begin{array}{l}\text { Form Approved } \\
\text { OMB No. 0704-0188 }\end{array}$ \\
\hline \multicolumn{6}{|c|}{ 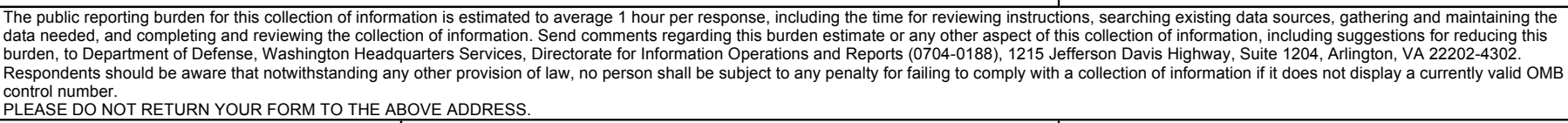 } \\
\hline \multicolumn{2}{|c|}{$\begin{array}{l}\text { 1. REPORT DATE (DD-MM-YYYY) } \\
01-03-2010\end{array}$} & \multicolumn{3}{|c|}{$\begin{array}{l}\text { 2. REPORT TYPE } \\
\text { Technical Memorandum }\end{array}$} & 3. DATES COVERED (From - To) \\
\hline \multirow{3}{*}{\multicolumn{5}{|c|}{$\begin{array}{l}\text { 4. TITLE AND SUBTITLE } \\
\text { Aerodynamic Simulation of Runback Ice Accretion }\end{array}$}} & 5a. CONTRACT NUMBER \\
\hline & & & & & 5b. GRANT NUMBER \\
\hline & & & & & 5c. PROGRAM ELEMENT NUMBER \\
\hline \multirow{3}{*}{\multicolumn{5}{|c|}{$\begin{array}{l}\text { 6. AUTHOR(S) } \\
\text { Broeren, Andy, P.; Whalen, Edward, A.; Busch, Greg, T.; Bragg, Michael, B. }\end{array}$}} & 5d. PROJECT NUMBER \\
\hline & & & & & 5e. TASK NUMBER \\
\hline & & & & & $\begin{array}{l}\text { 5f. WORK UNIT NUMBER } \\
\text { WBS 457280.02.07.03.02.02 }\end{array}$ \\
\hline \multicolumn{5}{|c|}{$\begin{array}{l}\text { 7. PERFORMING ORGANIZATION NAME(S) AND ADDRESS(ES) } \\
\text { National Aeronautics and Space Administration } \\
\text { John H. Glenn Research Center at Lewis Field } \\
\text { Cleveland, Ohio 44135-3191 }\end{array}$} & $\begin{array}{l}\text { 8. PERFORMING ORGANIZATION } \\
\text { REPORT NUMBER } \\
\text { E-17042 }\end{array}$ \\
\hline \multirow{2}{*}{\multicolumn{5}{|c|}{$\begin{array}{l}\text { 9. SPONSORING/MONITORING AGENCY NAME(S) AND ADDRESS(ES) } \\
\text { National Aeronautics and Space Administration } \\
\text { Washington, DC 20546-0001 }\end{array}$}} & $\begin{array}{l}\text { 10. SPONSORING/MONITOR'S } \\
\text { ACRONYM(S) } \\
\text { NASA }\end{array}$ \\
\hline & & & & & $\begin{array}{l}\text { 11. SPONSORING/MONITORING } \\
\text { REPORT NUMBER } \\
\text { NASA/TM-2010-215676 }\end{array}$ \\
\hline \multicolumn{6}{|c|}{$\begin{array}{l}\text { 12. DISTRIBUTION/AVAILABILITY STATEMENT } \\
\text { Unclassified-Unlimited } \\
\text { Subject Categories: } 01,02 \text {, and } 03 \\
\text { Available electronically at http://gltrs.grc.nasa.gov } \\
\text { This publication is available from the NASA Center for AeroSpace Information, 443-757-5802 }\end{array}$} \\
\hline \multicolumn{6}{|c|}{$\begin{array}{l}\text { 13. SUPPLEMENTARY NOTES } \\
\text { Portions of this material were published as AIAA-2009-4261. Also published as DOT/FAA/AR-09/26 by U.S. Department of } \\
\text { Transportation, Federal Aviation Administration, Dec. } 2009 \text {. }\end{array}$} \\
\hline \multicolumn{6}{|c|}{$\begin{array}{l}\text { 14. ABSTRACT } \\
\text { This report presents the results of recent investigations into the aerodynamics of simulated runback ice accretion on airfoils. Aerodynamic } \\
\text { tests were performed on a full-scale model using a high-fidelity, ice-casting simulation at near-flight Reynolds }(R e) \text { number. The ice-casting } \\
\text { simulation was attached to the leading edge of a } 72 \text {-in. }(1828.8-\mathrm{mm}) \text { chord NACA } 23012 \text { airfoil model. Aerodynamic performance tests } \\
\text { were conducted at the ONERA F1 pressurized wind tunnel over a Reynolds number range of } 4.7 \times 10^{6} \text { to } 16.0 \times 10^{6} \text { and a Mach }(M) \text { number } \\
\text { range of } 0.10 \text { to } 0.28 \text {. For } R e=16.0 \times 10^{6} \text { and } M=0.20 \text {, the simulated runback ice accretion on the airfoil decreased the maximum lift } \\
\text { coefficient from } 1.82 \text { to } 1.51 \text { and decreased the stalling angle of attack from } 18.1^{\circ} \text { to } 15.0^{\circ} \text {. The pitching-moment slope was also increased } \\
\text { and the drag coefficient was increased by more than a factor of two. In general, the performance effects were insensitive to Reynolds } \\
\text { number and Mach number changes over the range tested. Follow-on, subscale aerodynamic tests were conducted on a quarter-scale NACA } \\
23012 \text { model (18-in. ( } 457.2-\mathrm{mm}) \text { chord) at } R e=1.8 \times 10^{6} \text { and } M=0.18 \text {, using low-fidelity, geometrically scaled simulations of the full-scale } \\
\text { casting. It was found that simple, two-dimensional simulations of the upper- and lower-surface runback ridges provided the best } \\
\text { representation of the full-scale, high Reynolds number iced-airfoil aerodynamics, whereas higher-fidelity simulations resulted in larger } \\
\text { performance degradations. The experimental results were used to define a new subclassification of spanwise ridge ice that distinguishes } \\
\text { between short and tall ridges. This subclassification is based upon the flow field and resulting aerodynamic characteristics, regardless of the } \\
\text { physical size of the ridge and the ice-accretion mechanism. }\end{array}$} \\
\hline \multicolumn{6}{|c|}{$\begin{array}{l}\text { 15. SUBJECT TERMS } \\
\text { Aircraft icing; Airfoil; Aerodynamic performance }\end{array}$} \\
\hline \multicolumn{3}{|c|}{ 16. SECURITY CLASSIFICATION OF: } & $\begin{array}{l}\text { 17. LIMITATION OF } \\
\text { ABSTRACT }\end{array}$ & $\begin{array}{l}\text { 18. NUMBER } \\
\text { OF }\end{array}$ & $\begin{array}{l}\text { 19a. NAME OF RESPONSIBLE PERSON } \\
\text { STI Help Desk (email:help@sti.nasa.gov) }\end{array}$ \\
\hline $\begin{array}{l}\text { a. REPORT } \\
\text { U }\end{array}$ & $\begin{array}{l}\text { b. ABSTRACT } \\
\text { U }\end{array}$ & $\begin{array}{l}\text { c. THIS } \\
\text { PAGE } \\
\text { U }\end{array}$ & UU & $\begin{array}{l}\text { PAGES } \\
50\end{array}$ & $\begin{array}{l}\text { 19b. TELEPHONE NUMBER (include area code) } \\
443-757-5802\end{array}$ \\
\hline
\end{tabular}



